\title{
Mathematical Simulations and On-Road Experimentations of the Vibration Energy Harvesting from Mining Dump Truck Hydro-Pneumatic Suspension
}

\author{
Wenguang $W u\left(\mathbb{D},{ }^{1,2}\right.$ Sha Zhang, ${ }^{3}$ and Zhiyong Zhang $\mathbb{D}^{1,2}$ \\ ${ }^{1}$ Changsha University of Science \& Technology, College of Automotive \& Mechanical Engineering, Changsha, \\ Hunan Province, China \\ ${ }^{2}$ Hunan Key Laboratory of Smart Roadway and Cooperative Vehicle-infrastructure Systems, Changsha, Hunan Province, China \\ ${ }^{3}$ CRRC Zhuzhou Institute, Zhuzhou, Hunan Province, China
}

Correspondence should be addressed to Zhiyong Zhang; zzy04@163.com

Received 11 July 2019; Revised 3 October 2019; Accepted 17 October 2019; Published 11 November 2019

Academic Editor: Peter Múčka

Copyright ( $\odot 2019$ Wenguang Wu et al. This is an open access article distributed under the Creative Commons Attribution License, which permits unrestricted use, distribution, and reproduction in any medium, provided the original work is properly cited.

\begin{abstract}
Running on an unpaved road, the truck's vibration is weakened by the HPS (hydro-pneumatic suspension) and transformed into thermal energy which was finally dissipated in the air. This paper is aimed to discuss the energy harvesting potential from the truck HPS on random road excitation. In this manner, a quarter-truck model was built and the kinetic energy method that can be used to calculate the power of the dissipated energy was proposed. The dissipated instantaneous power (The peak value is $180 \mathrm{~kW}$ ) and average power $(12 \mathrm{~kW})$ were analyzed which showed 15 -fold of difference. The different road class analysis results showed that the E-class road excited 4-fold of power than that of D-class road. The influence of damping and stiffness on the dissipation power was analyzed. The results showed that the power excited by the D-class road is less sensitive than the E-class road. Furthermore, it is interesting that the results also show that the value of average dissipated power when running on E-class road is very close to the speed value, respectively. The real road test of the truck was carried out in an open pit mine and verified the simulation results. The final results demonstrated that the vibrational energy that harvested from the HPS could reduce oil consumption by about $4 \%$ in theory.
\end{abstract}

\section{Introduction}

The energy crisis and environmental pollution are currently the most acute and sensitive problems around the world. As the population has increased, energy consumption has reached a new level. According to the IEA [1], the world's oil demand is about 9800 barrels per day, and the tremendous energy consumption is the result of a large number of vehicles being driven. Recycling energy from vehicles became the hottest topic in the academic fields of engineering science and technology research.

When running on a rough road, the vibration of the truck is generated due to the excitation from the road, which is then absorbed by the suspension and transmitted to the vehicle body. This is especially evident for a mining dump truck, which often runs on an unpaved road, and the range of vehicle vibration, acceleration, and velocity are usually very wide. The vibrational energy is often absorbed by tires and vehicle suspensions, but the tires only absorb a few amount of the vibrational energy for its small damping; the rest of the energy is absorbed by the suspension and dissipated by thermal energy. Retrieving the wasted vibrational energy is an efficient way of harvesting the vehicle's energy. If the energy that is dissipated by the suspension can be harvested and reused for the vehicle's electrical system, then the energy utilization efficiency of the whole vehicle will increase clearly.

There has been much research carried out with regard to energy harvesting for different vehicles and the different methods of doing so [2-4]. This research has called for 
unusual discussions about harvesting a vehicle's energy, and the theoretical research has showed that there are vast prospects for the application of the energy. In total, the research has discussed three methods to harvest vibrational energy from vehicles: a mechanical facility used for the kinetic-electric energy transfer method, piezoelectric facilities, and a thermal-electric energy transfer method [5].

The piezoelectric module is widely used in harvesting ocean wave energy and tire monitor systems. The Tire pressure monitoring system (TPMS) can be used to measure some important parameters, such as tire pressure, tire deflection, vehicle speed, and tire force. Therefore, the wireless TPMS and battery-less TPMS system were invented and have been widely used in modern cars [6-9]. Ocean wave energy harvesting facilities have been displayed in the literature [10-12], which are equipped with a piezoelectric module; the results showed that the mechanism had significantly improved the efficiency of the system.

A thermoelectric material that can be used to convert thermal energy into electrical power has been presented in the literature [13]. It is the perfect material to use to recycle the wasted thermal energy that is widespread in vehicles. Therefore, an automobile exhaust thermoelectric generator has been tested in a GMC Sierra pick-up truck [14]. A mathematical model of the thermoelectric generator using the exhaust gas, which analyzed the impact of the relevant factors on the output power and efficiency, was presented in the literature [15]. A thermoelectric device, equipped with a hot pipe and a cold pipe to increase the system's efficiency, has been presented in the literature [16]. Computational fluid research has been carried out to increase the efficiency of the system; the temperature distribution, the power generation, and the back pressure were simulated in the numerical model, and the total mass of the facility was also optimized [17].

There are concerns with energy harvesting from different vehicles [18]. Potential energy harvesting of a heavy-duty truck is researched by the numerical investigation method [19]. A shock absorber with an integrated linear generator unit and a fluid damper has been presented in the literature [20]. Mechanical amplification was used in the linear generator unit to transform the kinetic energy to electrical power at high efficiency [21]. Similarly, the Bose Company demonstrated an active suspension system that used a linear motor to generate damping force to reduce the vibration of the suspension [22]. A shock absorber, which converts the up-and-down linear motion of the suspension movement into unidirectional rotation, was presented in the literature [23], and then, a generator was used to convert the kinetic energy to electrical power. Another method using an electrohydraulic damper has been presented in the literature [24-26], which used a motor that was driven by the hydraulic force which was produced by the motion of the suspension, and the hydraulic force could be used as the damping force. Furthermore, a mechanism of a magnet moving in a coil, used as a force actuator and an energy harvester, was also presented in the literature [27]. To the traditional shock absorber, the vibrations of SUV were measured in campus, the random road excitation, and bump excitation conditions were considered [28].

It can be concluded that the mechanism can be used as both a force actuator and a kinetic energy recycling system. With this mechanism, the suspension can be seen as active suspension, and the harvested energy can provide power to the electrical system. This will enhance the vehicle performance and the fuel economy, but this will increase the weight of the suspension, and the reliability of the suspension should also be considered. Therefore, suspension with a simple structure and high reliability is a necessary requirement. Active suspension is clearly not suitable for a mining dump truck because of the huge loads involved; however, a simple and reliable suspension system with an energy harvesting function would be desirable.

As the vehicle's vibrational energy is absorbed by the suspension, and the kinetic energy is transformed into heat energy, it would appear that the energy can be regenerated by the thermoelectric module. The average power and instantaneous power were calculated in this article; the results showed 15-fold of their differences. It answered how much energy is prospected to being harvested of the HPS, and the article also presented a comprehensive on the influence of stiffness and damping parameters to potential harvested energy. Furthermore, this article rendered a real road test and data analysis of a mining dump truck. This study will provide a good method to evaluate the power of energy harvesting from HPS and to demonstrate the influence of the harvesting potential.

\section{Method, Design and Model}

2.1. Energy Harvesting Method. As shown in Figure 1, when running on the rugged road of an open pit mine, the vibration amplitude of the truck is so large that the suspensions need to absorb massive energy to weaken it. The absorbed energy is then transformed into thermal energy and then the oil of HPS is warmed up. The thermal energy is radiated into the ambient air. An energy recycling system has been proposed in this paper to harvest the thermal energy and reuse it.

As shown in Figure 2, the main idea behind the HPS energy harvesting system is as follows:

(1) When running on a rough road, the tires' vibrations transmit to the vehicle body through the suspension, and the level of the vibration is influenced by the vehicle speed and the road roughness.

(2) The vibration is weakened by the HPS which transformed the vibrational energy into thermal energy and stored it in the oil.

(3) The heat is transferred into the air by means of thermal conduction and thermal radiation, and it passes through several Seebeck modules, which have been installed on the surface of the shock absorber. When the temperature differential between the surface of the shock absorber and the air reaches a certain value, the Seebeck module will generate electrical power. 


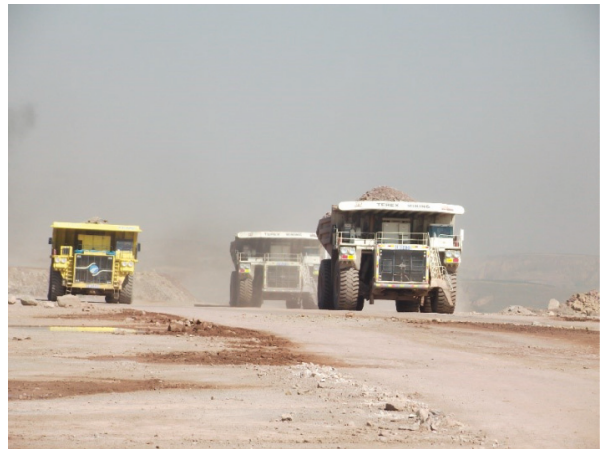

FIgURE 1: Real road surface of an open pit mine environment.

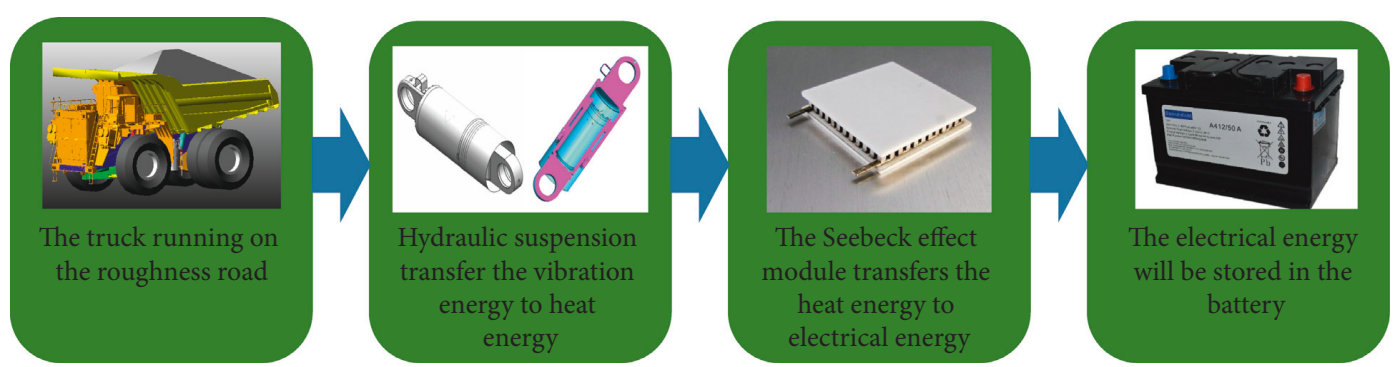

FIGURE 2: Schematic chart of the energy harvesting flow through the dump truck suspension.

(4) The electrical power can then be stored in a battery to benefit the vehicle's electrical system.

2.2. System Layout. As shown in Figure 3, the proposed energy harvesting system consisted of a HPS, thermal grease, Seebeck modules, a temperature sensor, a rectifier, and a battery. The special characteristic of the thermal grease is the ability to keep the temperature of the suspension stable. If the temperature of the suspension is low, the thermal grease has low thermal conductivity. It is favorable to increasing the temperature of the suspension. If the suspension temperature is high, the thermal grease has high thermal conductivity, which is advantageous to its ability to emit heat.

2.3. Quarter-Truck Model. Having more degrees of freedom may be beneficial when evaluating the accuracy of a truck dynamics model. However, a quarter-truck model is often enough to use to analyze the acceleration and relative motion of suspension response [29]. And a point contact model is used in the quarter-truck model. The diagram of the quarter-truck model is shown in Figure 4. This model consisted of a rigid body, a nonlinear HPS, and a tire that behaved linearly. The model is only able to analyze the vertical vibration characteristic of the truck, where the nonlinear force is relevant to the relative velocity and the relative displacement between the piston and piston rod of the HPS.

According to the parameters that are provided by the manufacture, the nomenclature and the value of the parts are shown in Table 1.

The system possessed two degrees of freedom, and the mathematical equations for the system are shown as follows:

$$
\left\{\begin{array}{l}
F_{s}-m_{s} g-m_{s} \ddot{x}_{s}=0, \\
F_{s}+m_{t} g+m_{t} \ddot{x}_{t}-k_{t}\left(x_{t}-q\right)+c_{t}\left(\dot{x}_{t}-\dot{q}\right)=0,
\end{array}\right.
$$

where $F_{s}$ is the suspension's stiffness and damping force; $x_{s}$ is the displacement of sprung mass; $x_{t}$ is the displacement of unsprung mass; and $q$ is the road input.

2.4. Hydro-Pneumatic Suspension Model. In the quartertruck model, the stiffness and damping force of the suspension are calculated using two mathematical functions.

2.4.1. Suspension Stiffness. The stiffness force is related to the spring rate, the structural parameters of the suspension, and the pressure and volume of the nitrogen in it. When the piston and the piston rod move up and down relatively, the volume of the nitrogen can be given by

$$
V=V_{0}-A_{r} x
$$

where $V$ is the volume of nitrogen in working conditions; $V_{0}=h_{0} \cdot A_{p}$ is the volume of nitrogen in the original condition, and $h_{0}$ is the height of nitrogen in the empty condition; $A_{r}$ is the area of the piston rod; and $x=x_{s}-x_{t}$ is the relative displacement of the suspension. Due to the mass of the gas is a constant, the stiffness can be given by

$$
F_{k}=\frac{k P_{0} V_{0} A_{r}^{2}}{\left(V_{0}-A_{r} x\right)^{n+1}}
$$

where $k$ is the air's polytropic coefficient, when the truck is running on a road that induces a low frequency, $k=1$, and $P_{0}$ is the original pressure of nitrogen, $P_{0}=m_{s} / A_{p}$. 


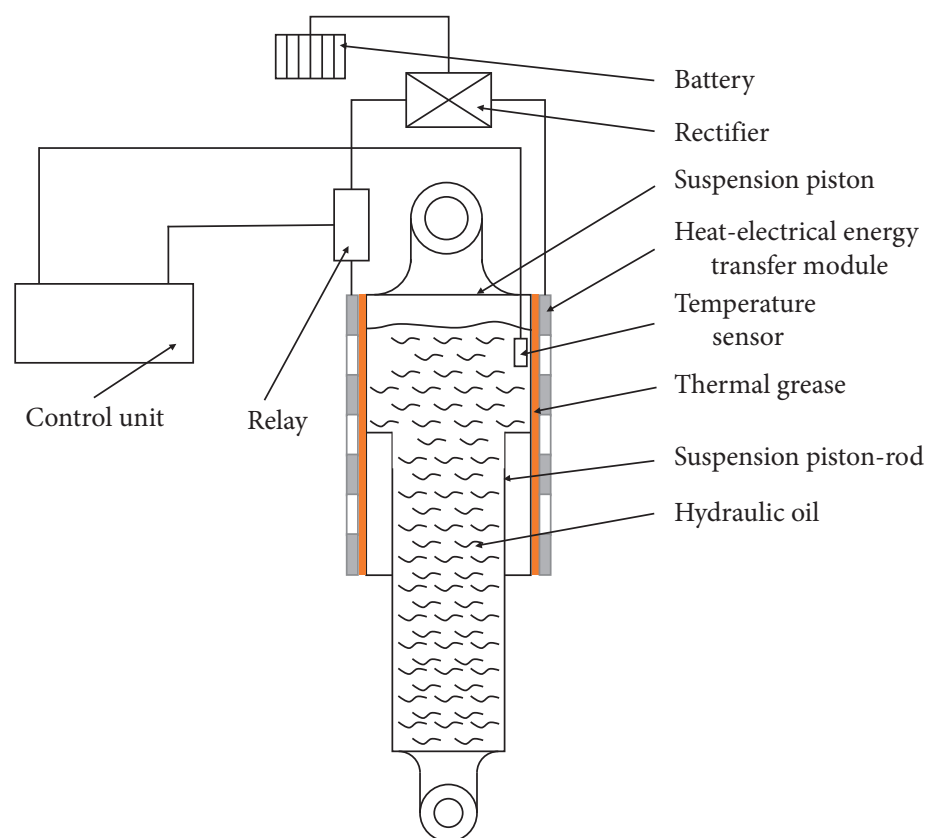

(a)

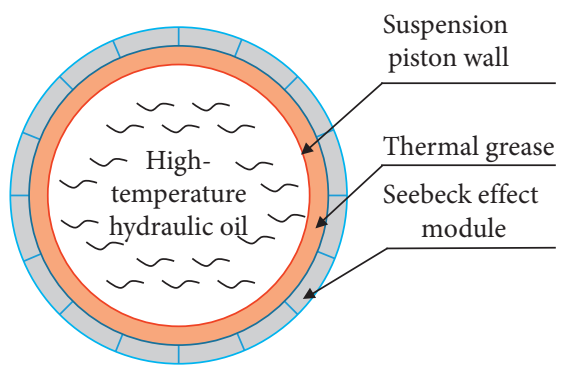

(b)

FIgURE 3: Schematic layout of the proposed thermoelectric energy-harvesting hydro-pneumatic absorber. (a) The layout of the system. (b) The cross section of the suspension.

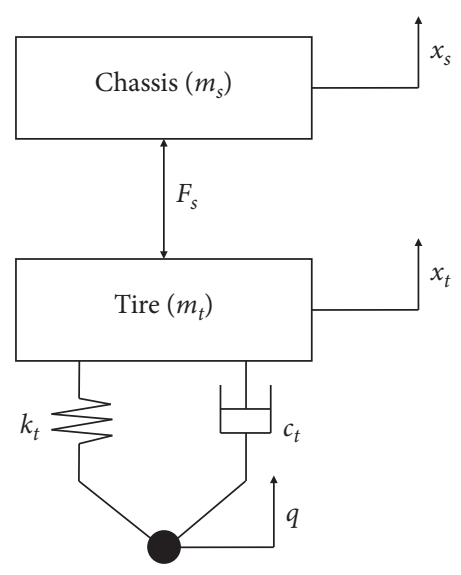

FIGURE 4: Quarter-truck model.

TABLE 1: Nomenclature of the mining dump truck.

\begin{tabular}{lcc}
\hline Parameter & Description & Value \\
\hline$m_{t}$ & Unsprung mass & $10750 \mathrm{~kg}$ \\
$m_{s}$ & Sprung mass in loaded condition & $52940 \mathrm{~kg}$ \\
$A_{p}$ & Area of the suspension piston & $1.0654 \times 10^{5} \mathrm{~mm}^{2}$ \\
$A_{r}$ & Area of the suspension piston rod & $8.5582 \times 10^{4} \mathrm{~mm}^{2}$ \\
$\rho$ & Density of the hydraulic oil & $890 \mathrm{~kg} / \mathrm{m}^{3}$ \\
$d_{c}$ & Diameter of the check value & $12.7 \mathrm{~mm}$ \\
$d$ & Diameter of the damping hole & $4.5 \mathrm{~mm}$ \\
$A_{c}$ & Area of the check value & $113.1 \mathrm{~mm}^{2}$ \\
$A_{d}$ & Area of the damping hole & $16 \mathrm{~mm}^{2}$ \\
$C_{c}$ & Flow rate coefficient & 0.7908 \\
$k_{t}$ & Stiffness of the tire & $3.3 \times 10^{6} \mathrm{~N} / \mathrm{mm}$ \\
$c_{t}$ & Damping rate of the tire & $1 \times 10^{4} \mathrm{~N} /(\mathrm{mm} / \mathrm{s})$ \\
\hline
\end{tabular}

The stiffness characteristic of front suspension with different $h_{0}$ in loaded condition is shown in Figure 5. It can be seen from the figure that the lower $h_{0}$ will bring a larger stiffness. The stiffness increases clearly when the compression stroke reaches $50 \mathrm{~mm}$. The height of nitrogen has marker influence on the stiffness.

2.4.2. Suspension Damping. As the diameter of the damping valve is $4.5 \mathrm{~mm}$, and the length of the valve is $36 \mathrm{~mm}$, the length-diameter ratio is 9 . The flow field of the damping value can be calculated using the slender-thick-hole method; the pressure drop coefficient equation can be written as

$$
\Delta p=\frac{128 \rho v l q_{0}}{\pi d^{4}}
$$

where $\rho$ is the density of the oil; $l$ is the length of the damping valve; $v$ is the kinetic viscosity of the oil; $q_{0}$ is the flow rate; and $d$ is the diameter of the damping valve.

When $\operatorname{Re}=v d / v$ and $q=\pi d^{2} v / 4$, the pressure drop can be written as

$$
\Delta p=\frac{\lambda l \rho v^{2}}{2 d}
$$

where $v$ is the flow rate and $\lambda$ is the damping coefficient; the $\lambda$ value can be calculated by the following equation:

$$
\lambda=\left[1.14-2 \lg \left(\frac{\Delta}{d}+\frac{21.25}{\left(579(\Delta / d)^{(9 / 8)}\right)^{0.9}}\right)\right]^{-2},
$$

where $\Delta$ is the roughness of the throttling hole, $\Delta=0.04$. 


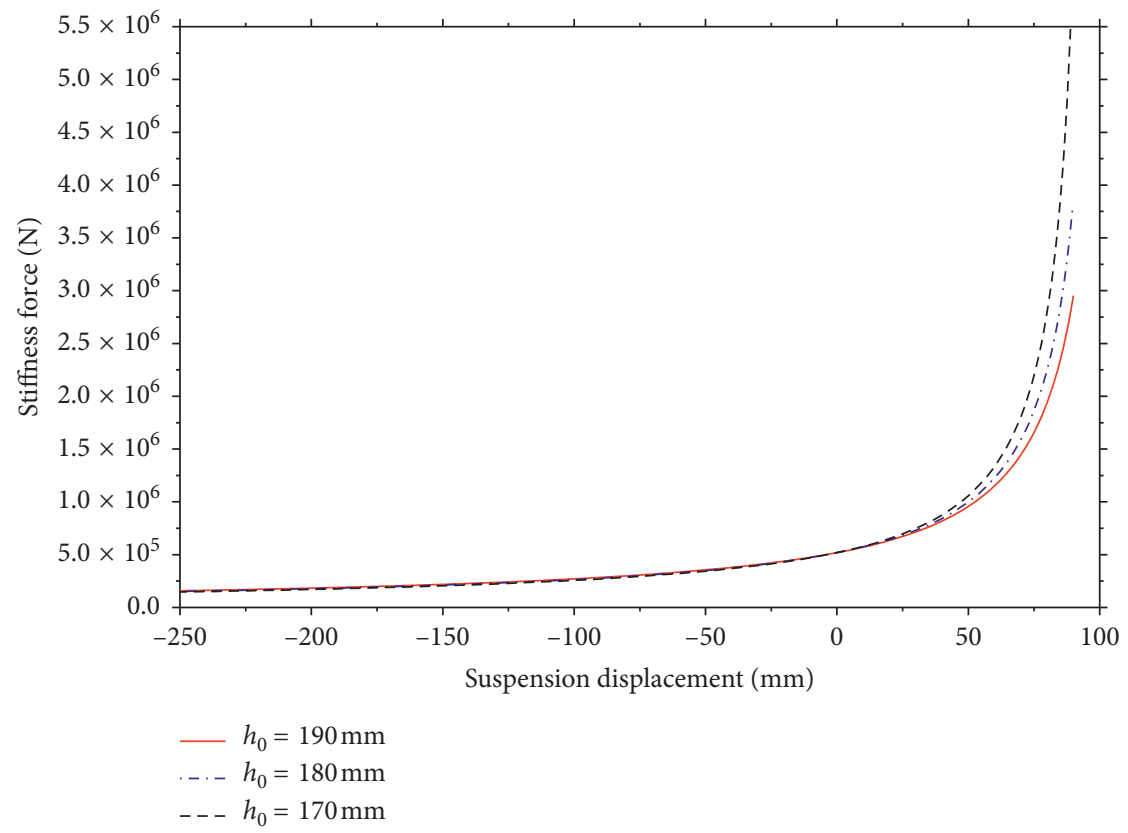

FIgURE 5: Stiffness characteristic of the front suspension.

According to the relative velocity between the suspension's piston and the piston rod, the flow rate equation can be written as follows:

$$
v=\frac{\dot{x} A_{0}}{\left(C_{c} A_{d}+C_{c} A_{c}(0.5+0.5 \operatorname{sign}(\dot{x}))\right)},
$$

where $A_{0}=A_{p}-A_{r}$ is the area of the annulus space and $\operatorname{sign}(\dot{x})$ is the sign function. When the suspension is in an extension stroke, and the check valve is closed, $\operatorname{sign}(\dot{x})=-1$; and when the suspension is in a compression stroke, the check valve is opened, $\operatorname{sign}(\dot{x})=1 ; A_{c}$ is the area of the check valve; $A_{d}$ is the area of the damping valve; $C_{c}$ is the flow rate of the check valve and damping valve. According to Pascal's law, the equation of the damping force can be written as follows:

$$
F_{c}=\frac{\lambda l \rho A_{0}^{3} \dot{x}^{2} \operatorname{sign}(\dot{x})}{2 d\left(C_{c} A_{d}+C_{c} A_{c}(0.5+0.5 \operatorname{sign}(\dot{x}))\right)^{2}} .
$$

The damping characteristic of the front suspension with different damping valve diameters $\left(d_{c}\right)$ can be seen in Figure 6. It can be concluded from the figure that as the damping valve diameter decreases, the damping force increases clearly. The damping force in extension stroke is larger than that in compression stroke critically. The diameter of the damping hole has strong influence on the damping.

2.5. Method of Calculating the Dissipated Energy. Vibration is always weakened by the oil in a HPS, and the vibrational energy is converted into thermal energy, which can be calculated from either the vibrational energy or the thermal energy. The vibrational energy can be calculated as

$$
E=F_{c} \cdot x \text {, }
$$

where $F_{c}$ is the damping force.
In the experiment, the sampling frequency of the sensor is $512 \mathrm{~Hz}$, and the suspension's relative velocity is always less than $2 \mathrm{~m} / \mathrm{s}$. In an extremely short period (1/512 s), the velocity can be regarded as a constant. In one sampling period, the instantaneous energy can be calculated as

$$
E_{i}=\frac{F_{c i} \dot{x}_{i}}{512}
$$

where $F_{c i}$ is the damping force at a given moment and $\dot{x}_{i}$ is the relative velocity of the suspension at the same moment. The total energy is

$$
E=\sum_{i=1}^{i=512 * \text { time }} \frac{F_{c i} \dot{x}_{i}}{512}
$$

The average energy is

$$
E_{\text {ave }}=\frac{E}{\text { time }}
$$

2.6. Random Road Surface Excitation. The surface roughness of a road can be characterized by a power spectral density function shown in the standard ISO 8068-2016 [30]; the suggested function can be written as

$$
G_{d}(n)=G_{d}\left(n_{0}\right)\left(\frac{n}{n_{0}}\right)^{-w},
$$

where $n$ is the spatial frequency, which shows the wavelength of the surface roughness, and $n_{0}=0.1 \mathrm{~m}^{-1} ; G_{d}\left(n_{0}\right)$ is the road roughness coefficient, the coefficient value of different road classes have been shown in Table 2 .

It should be taken into consideration that the truck operates on unpaved roads in an open pit mine all year round. The road surface is often damaged by water, and the conditions of the roads are terrible. D-class and E-class roads 


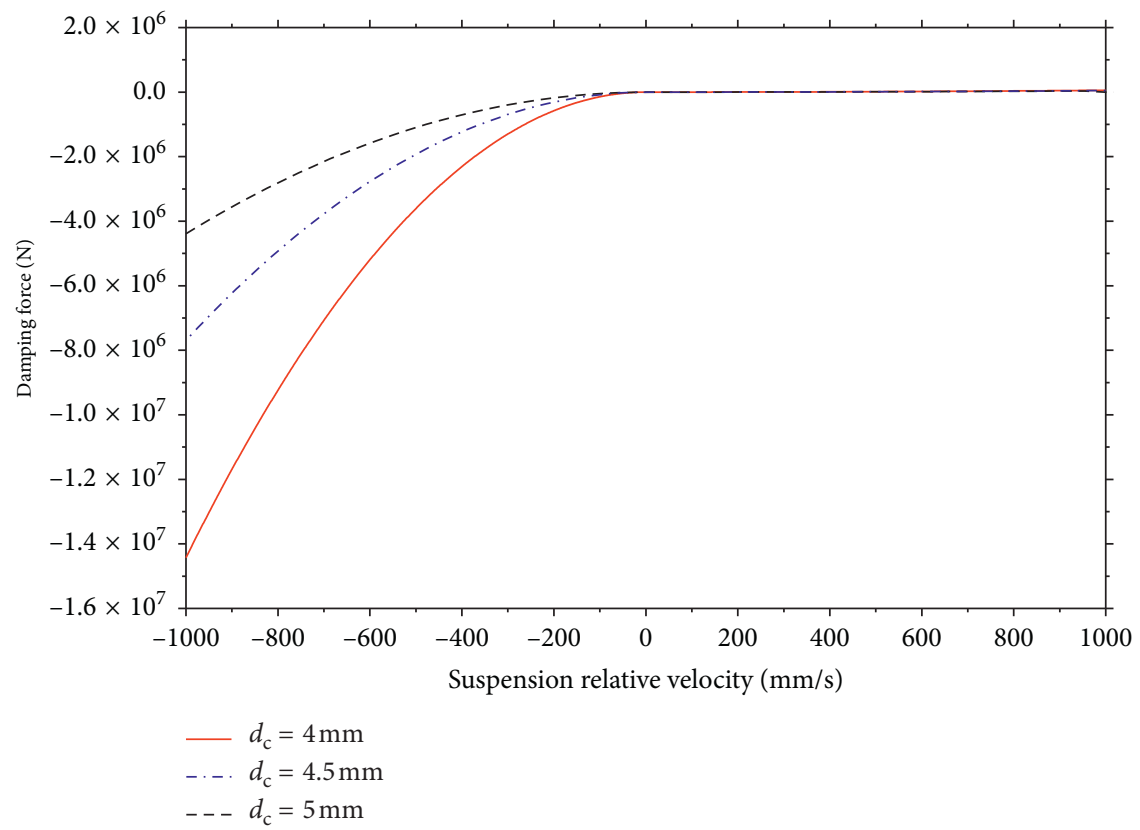

Figure 6: Damping characteristic of the front suspension.

TABLE 2: Standards of the road roughness classes.

\begin{tabular}{|c|c|c|c|}
\hline \multirow{2}{*}{$\begin{array}{l}\text { Road } \\
\text { class }\end{array}$} & \multicolumn{3}{|c|}{$\left(G_{d}\left(n_{0}\right) / 10^{-6} m^{3}\right)\left(n_{0}=0.1 m^{-1}\right)$} \\
\hline & $\begin{array}{l}\text { Lower } \\
\text { limit }\end{array}$ & $\begin{array}{l}\text { Mean } \\
\text { value }\end{array}$ & $\begin{array}{c}\text { Upper } \\
\text { limit }\end{array}$ \\
\hline A & - & 16 & 32 \\
\hline B & 32 & 64 & 128 \\
\hline $\mathrm{C}$ & 128 & 256 & 512 \\
\hline $\mathrm{D}$ & 512 & 1024 & 2048 \\
\hline $\mathrm{E}$ & 2048 & 4096 & 8192 \\
\hline $\mathrm{F}$ & 8192 & 16384 & 32768 \\
\hline G & 32768 & 65536 & 131072 \\
\hline $\mathrm{H}$ & 131072 & 262144 & - \\
\hline
\end{tabular}

are chosen in order to simulate the roughness of the roads. The roughness of the $\mathrm{D}$-class and E-class roads, in the time domain, is shown in Figure 7.

The laser or other devices may be a good choice to measure the road roughness and field profiles [31, 32], but the shortage of these devices makes it unable to measure the real road. In order to decide which road class is the most suitable for simulation, a comparison of RMS (root mean square) of the acceleration of the tire and the truck body between simulation and driving test results is proposed as shown in Figure 8. The figure shows that the vibration response of the wheel center and the truck body when simulating using the E-class road is the closest to test.

\section{Results and Discussion}

\subsection{Simulation Results}

3.1.1. Power Calculation. The response of the suspension's relative velocity with the $\mathrm{D}$-class and E-class roads input is shown in Figure 9. The peak velocity of the suspension is about $1.25 \mathrm{~m} / \mathrm{s}$ when the truck is running on the E-class road, while the maximum value is $0.8 \mathrm{~m} / \mathrm{s}$ when running on the D-class road. The acceleration of the suspension and its PSD (power spectral density) are shown in Figures 10 and 11, respectively. The acceleration of the suspension is about $5 \mathrm{~m} / \mathrm{s}^{2}$ when the truck is traveling on the E-class road, and the value was about $2 \mathrm{~m} / \mathrm{s}^{2}$ while traveling on the D-class road.

Figure 12 shows the predicted instantaneous power that is dissipated by one of four HPS for the two road classes. It can be seen from the figure that the instantaneous power of energy dissipated by the suspension is increased as the speed of the truck increased from 10 to $50 \mathrm{~km} / \mathrm{h}$.

Figure 13 shows the average power dissipated by four suspension units of the truck for a range of speed from 10 to $50 \mathrm{~km} / \mathrm{h}$. It can be seen from the figure that as the velocity increased, the average power of dissipated energy displayed an approximately linear characteristic increase for both the D-class and E-class roads.

Furthermore, from Figures 12 and 13, it can be seen that the average power of dissipated energy by the whole HPS systems (comprising four hydro-pneumatic suspension units) is only about $48 \mathrm{~kW}$, but the peak instantaneous power generated in one suspension is $180 \mathrm{~kW}$, which is 15 times the average power. If a truck is to be equipped with a real time energy-harvesting system, such as a piezoelectric module, the capacity of the system should be larger than $720 \mathrm{~kW}(180 \mathrm{~kW} \times 4=720 \mathrm{~kW})$, while about $48 \mathrm{~kW}$ of system capacity is needed, if the truck is equipped with the proposed energy harvesting system.

The average dissipated power of the suspension with speed from 10 to $50 \mathrm{~km} / \mathrm{h}$ on the D-class and E-class roads is shown in Table 3. It can be seen from the table that the average dissipated power when running on the E-class road is about 4 times that of driving on the D-class road. It is interesting that value of the average dissipated power on the E-class road is very close to the value of speed, respectively. 


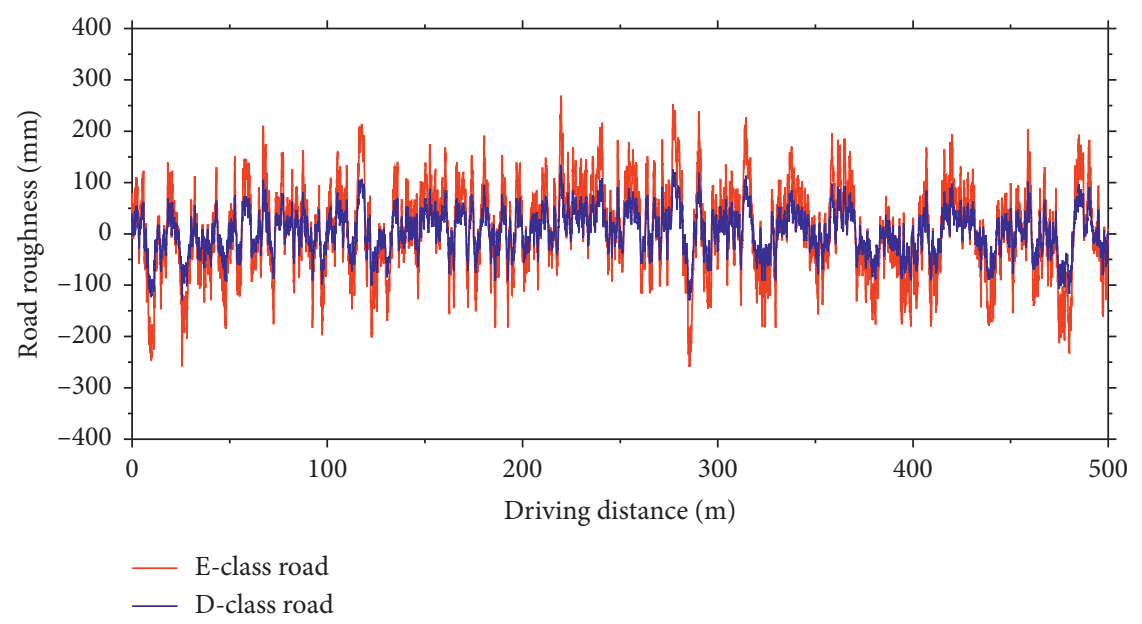

FIGURE 7: Road roughness at speed $50 \mathrm{~km} / \mathrm{h}$.

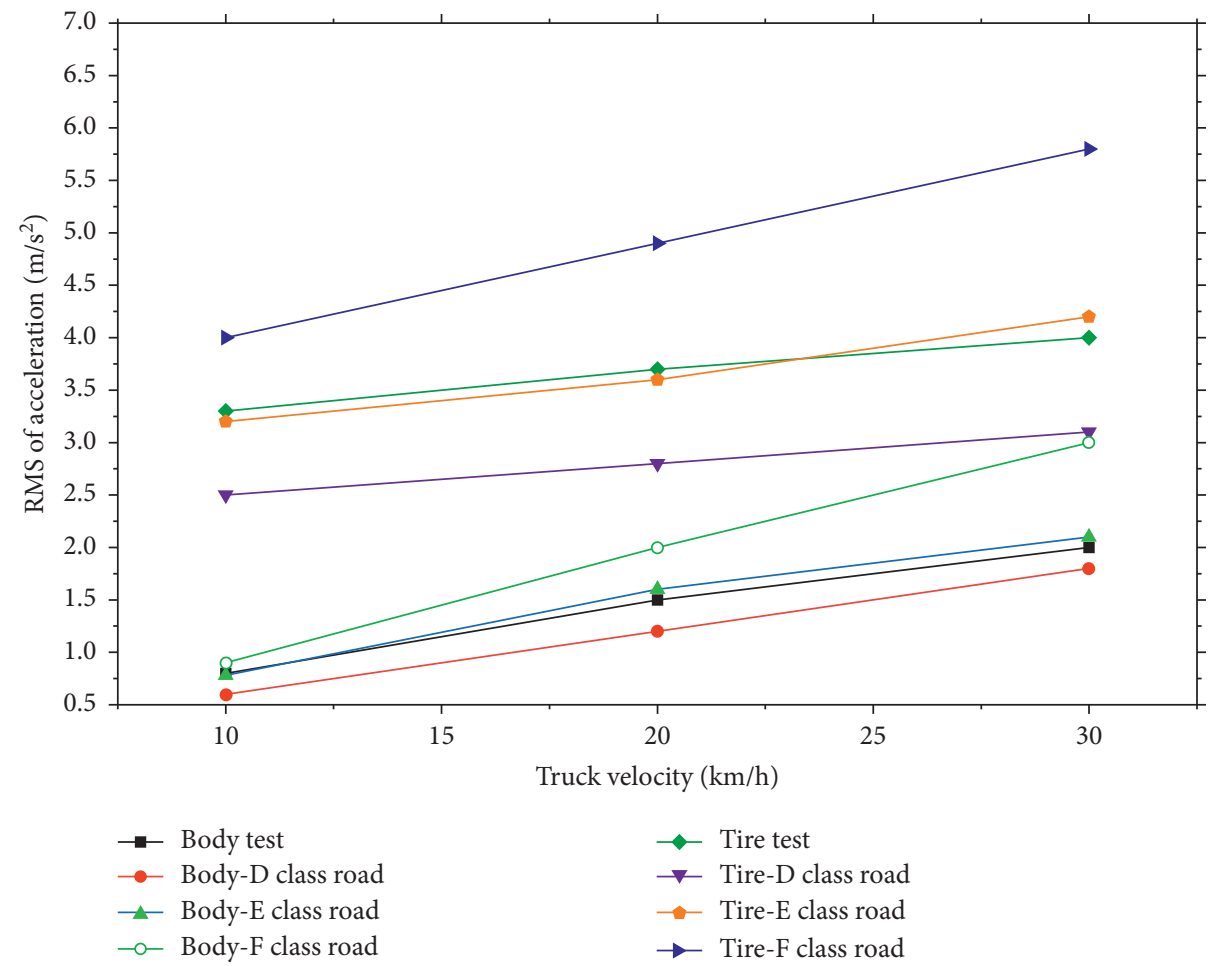

Figure 8: Acceleration comparison between experiment and simulation.

3.1.2. Analysis of the Influence by Stiffness and Damping. Average power comparison of different damping holes by one HPS is shown in Figure 14. When driving on the D-class road, the damping hole diameter was found to have small influence on the average power. It is not clear how the damping hole diameter influences the average power when driving on the E-class road. When the diameter is $4 \mathrm{~mm}$, the average power increases obviously, while the power stays constant if the diameter is $4.5 \mathrm{~mm}$ and $5 \mathrm{~mm}$.

The average dissipated energy of different nitrogen heights by one HPS is shown in Figure 15. When driving on the $\mathrm{D}$-class road, the nitrogen height was found to have a marginal impact to the average power. On the E-class road, the power is smaller than other conditions clearly when nitrogen height is $180 \mathrm{~mm}$.

To analyze how the stiffness and damping influenced the power, the RMS of acceleration of the sprung mass is proposed, as shown in Appendix Table 4 and 5. It can be concluded from the table that the average power is the marker related to the RMS. The power is influenced by the damping and stiffness.

3.2. Results of Truck Driving Experiment. The driving experiment of the truck was carried out in an open pit mine in the west of China, as shown in Figure 16. The experiment 


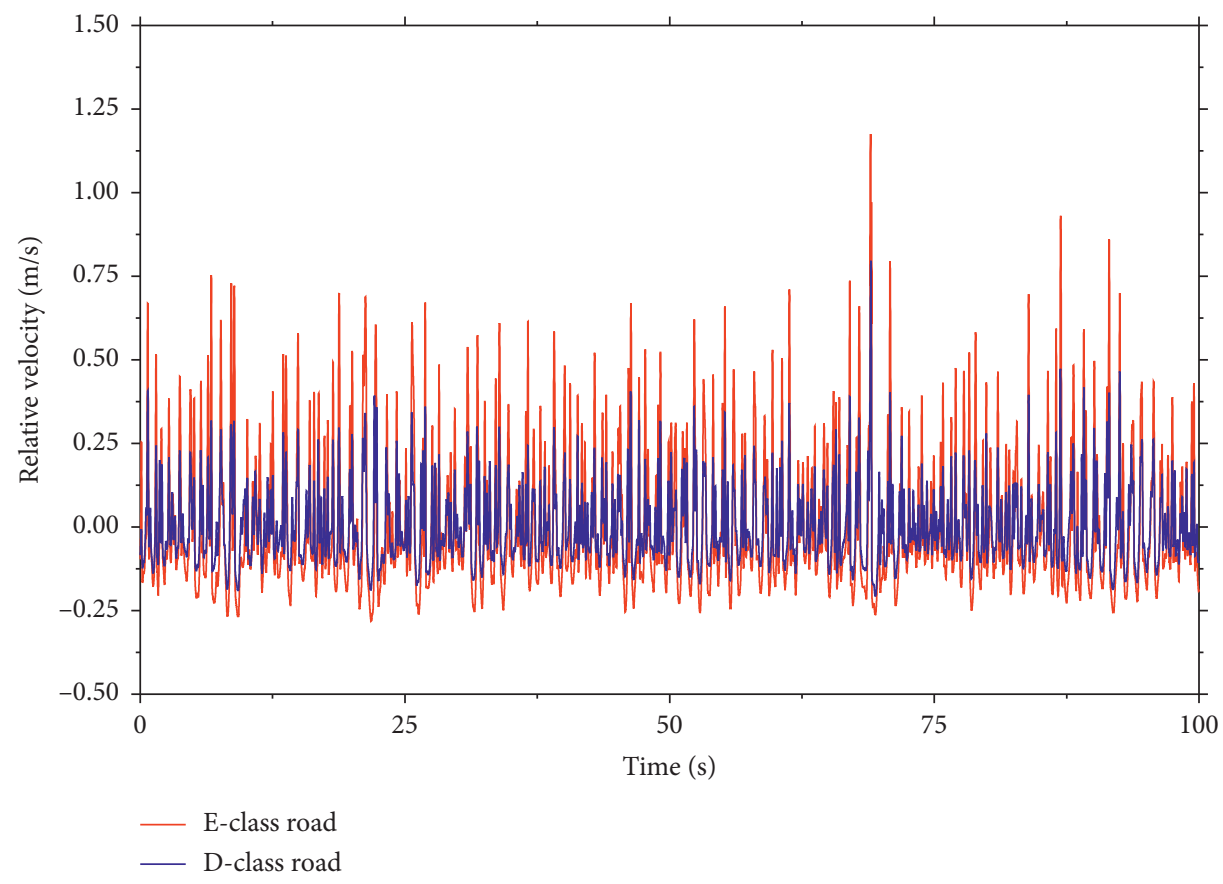

FIgURE 9: Relative suspension velocity at a speed of $50 \mathrm{~km} / \mathrm{h}$.

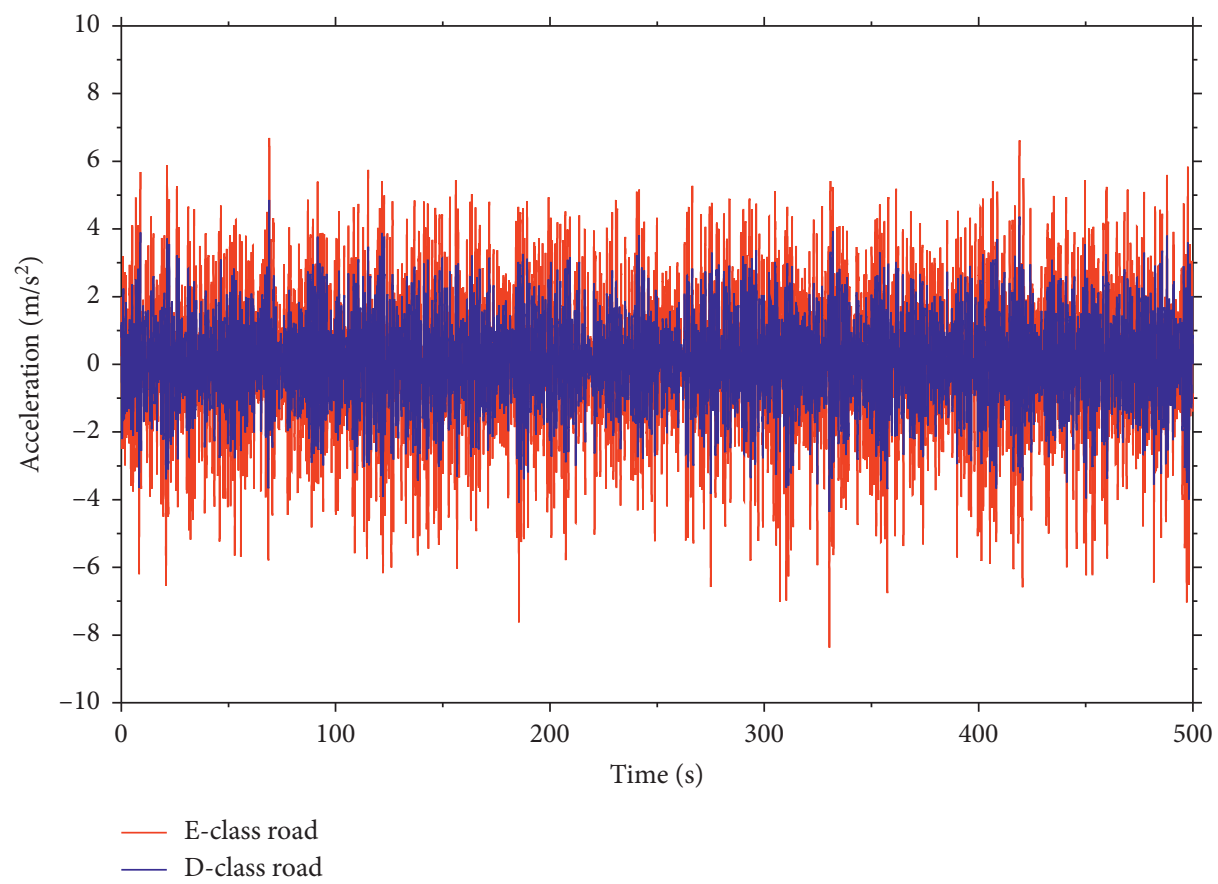

FIgURE 10: Acceleration of the sprung mass at a speed of $50 \mathrm{~km} / \mathrm{h}$.

devices are shown in Table 6. The accelerometers are used to measure the acceleration that separated all of truck, especially the engine and suspensions; the measurement points are shown in Figure 17 and the Table 7. To analyze the potential value of suspension harvested energy, the measured acceleration data of the upper suspension installation point and lower suspension installation point are adopted.
Equations (10) and (11) show that, in order to evaluate the energy dissipated by the suspension, the relative velocities of the suspensions are needed, which can be calculated from the measured acceleration data. The calculation method is as follows:

$$
y(r)=\sum_{k=0}^{N=1} \frac{2}{j 2 \pi k \Delta f} H(k) X(k) e^{(j 2 \pi k r / N)},
$$




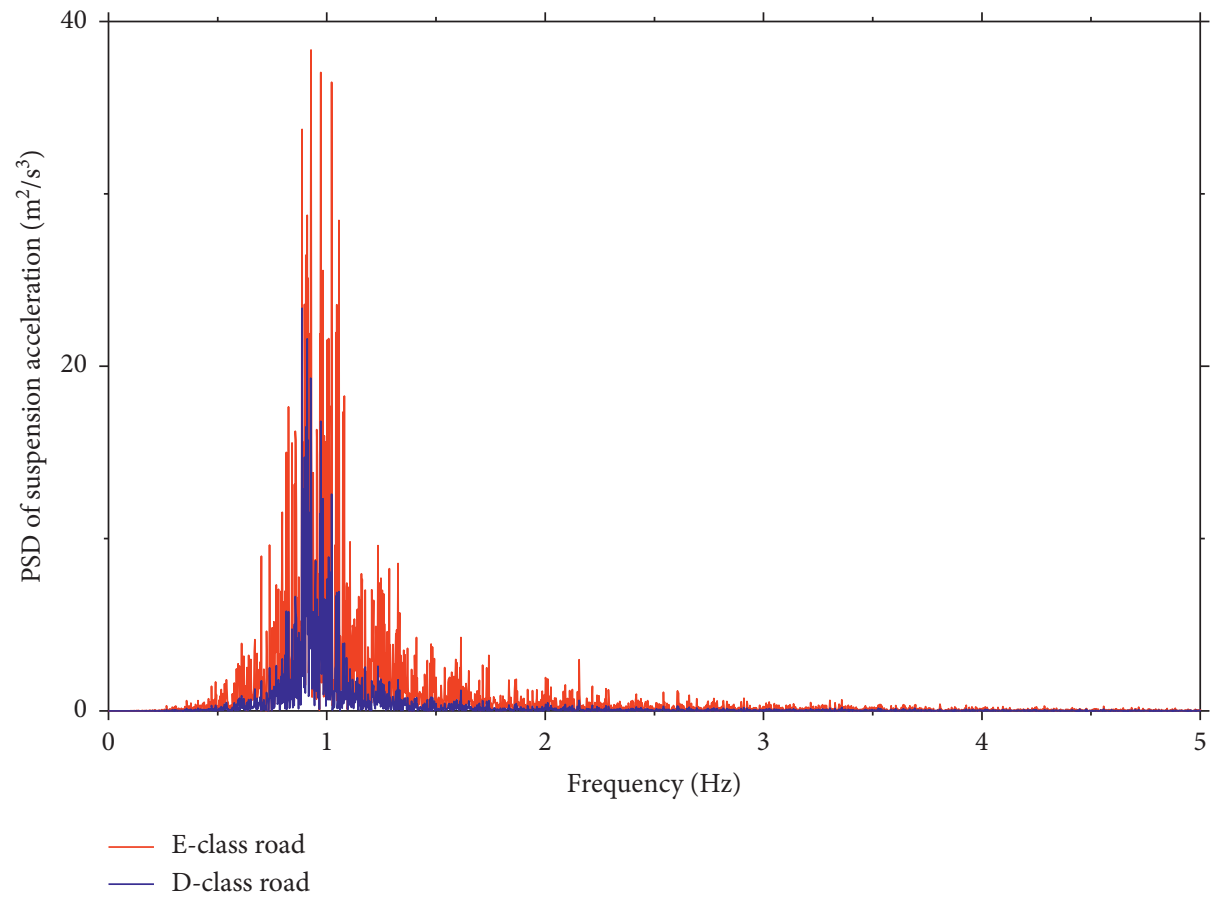

FIgURe 11: PSD of sprung mass at a speed of $50 \mathrm{~km} / \mathrm{h}$.
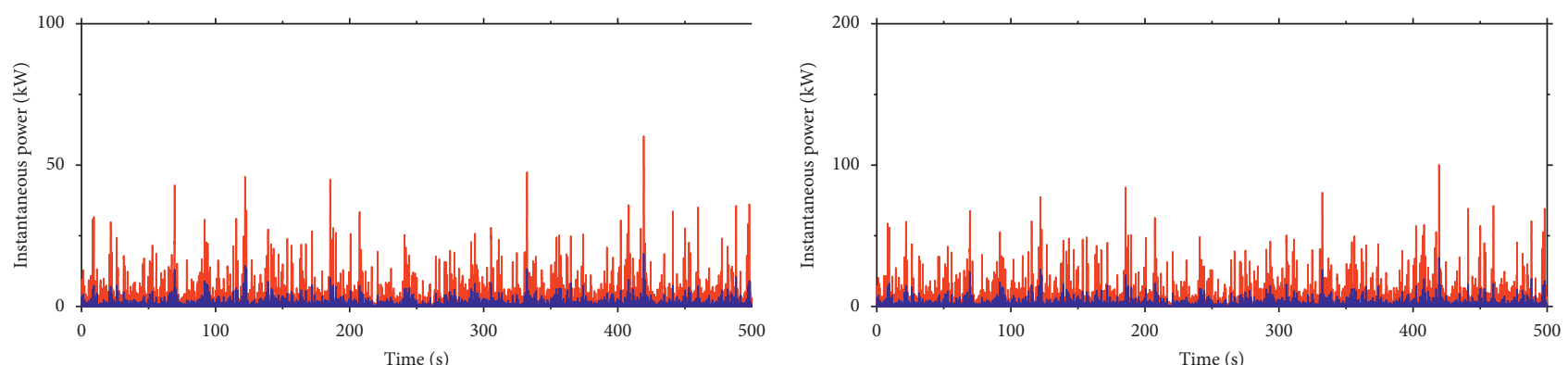

$10 \mathrm{~km} / \mathrm{h}$ on E-class road

_ $20 \mathrm{~km} / \mathrm{h}$ on E-class road

_ $20 \mathrm{~km} / \mathrm{h}$ on D-class road

(a)

(b)
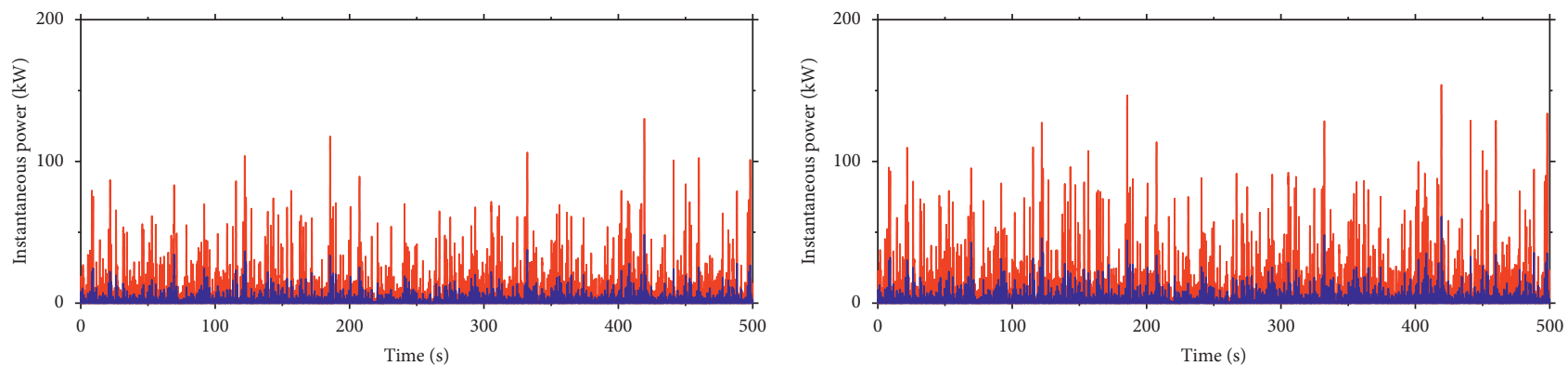

$30 \mathrm{~km} / \mathrm{h}$ on E-class road

— $40 \mathrm{~km} / \mathrm{h}$ on E-class Road

— $30 \mathrm{~km} / \mathrm{h}$ on D-class road

— $40 \mathrm{~km} / \mathrm{h}$ on D-class Road

(c)

(d)

Figure 12: Continued. 


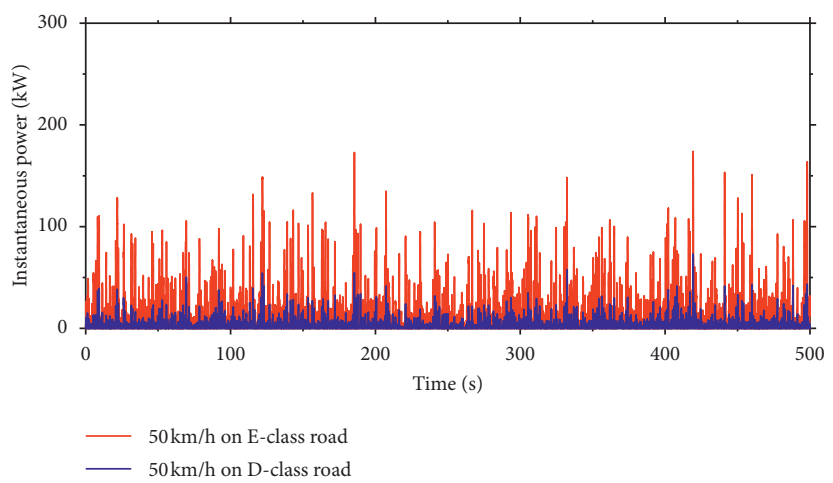

(e)

FigURE 12: Instantaneous power dissipated by the suspension at different speeds. (a) $10 \mathrm{~km} / \mathrm{h}$. (b) $20 \mathrm{~km} / \mathrm{h}$. (c) $30 \mathrm{~km} / \mathrm{h}$. (d) $40 \mathrm{~km} / \mathrm{h}$. (e) $50 \mathrm{~km} / \mathrm{h}$.

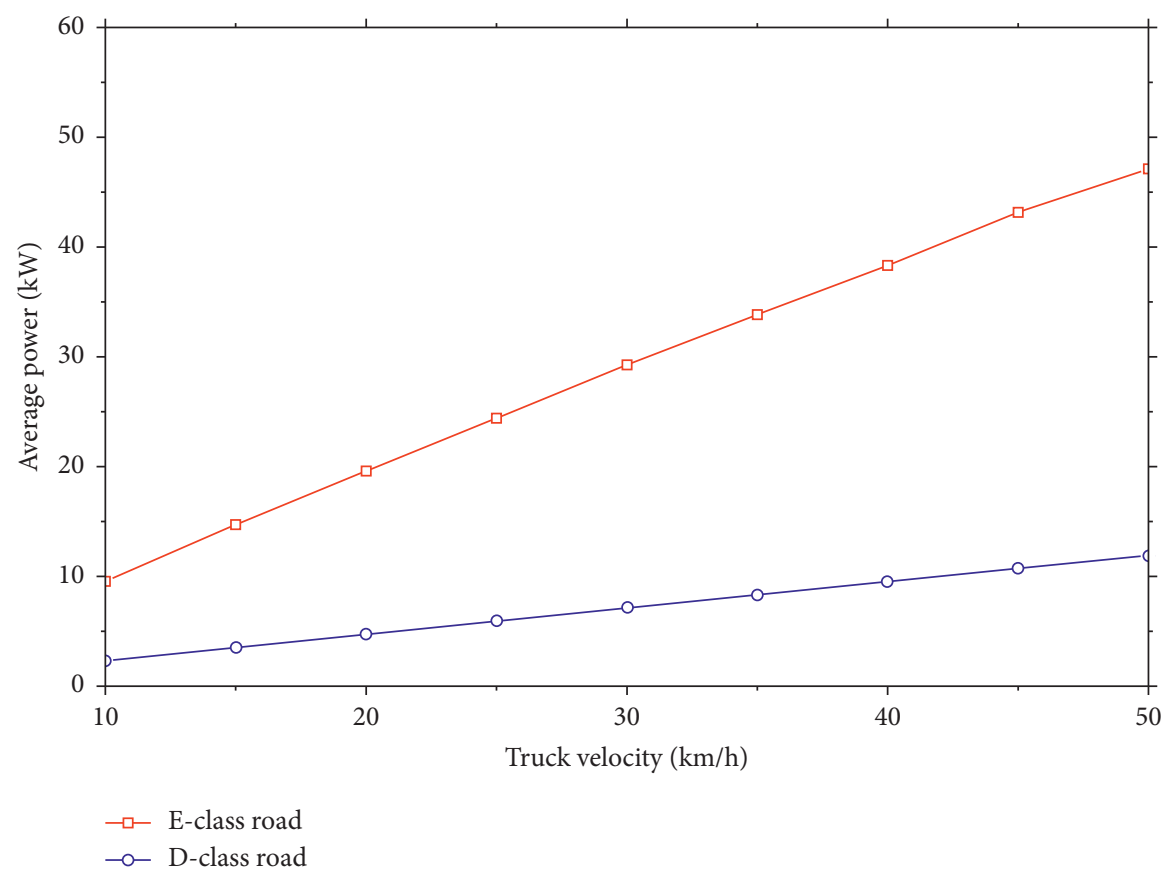

FIgURE 13: Average power dissipated by the suspension at different speeds.

TABle 3: Average power of different speeds.

\begin{tabular}{lccccccccc}
\hline $\begin{array}{l}\text { Speed } \\
(\mathrm{km} / \mathrm{h})\end{array}$ & 10 & 15 & 20 & 25 & 30 & 35 & 40 & 45 & 50 \\
\hline $\begin{array}{l}\text { D-class } \\
(\mathrm{kW})\end{array}$ & 2.32 & 3.52 & 4.72 & 5.92 & 7.12 & 8.32 & 9.52 & 10.72 & 11.92 \\
$\begin{array}{l}\text { E-class } \\
(\mathrm{kW})\end{array}$ & 9.56 & 14.72 & 19.6 & 24.4 & 29.28 & 33.84 & 38.32 & 43.16 & 47.12 \\
Ratio & 4.12 & 4.18 & 4.15 & 4.12 & 4.11 & 4.07 & 4.03 & 4.03 & 3.95 \\
\hline
\end{tabular}

where

$$
H(k)=\left\{\begin{array}{l}
1, \quad\left(f_{d} \leq k \Delta f \leq f_{u}\right), \\
0,
\end{array}\right.
$$

where $f_{d}$ and $f_{u}$ are the lower and upper termination frequencies, respectively, $X(k)$ is the Fourier transformation function of $x(r)$, and $\Delta f$ is the sampling frequency.
To verify the accuracy of the method, the relative suspension velocity outputted from the dynamic model and calculated using the above method is compared, as shown in Figure 18. It can be seen from the figure that the relative velocity calculated by these two methods is closely matched.

The relative velocity of the suspension and the instantaneous power with speeds $10-30 \mathrm{~km} / \mathrm{h}$ are shown in Figure 19. It can be seen from the figure that, as the speed increased from 10 to $30 \mathrm{~km} / \mathrm{h}$, the relative velocity of the left and right suspension units, as well as the instantaneous power increased. The maximum instantaneous power produced is about $200 \mathrm{~kW}$, and it is larger than that of the simulated value of $140 \mathrm{~kW}$ at the same speed. The average power dissipated by the suspension at speeds $10-30 \mathrm{~km} / \mathrm{h}$ is shown in Figure 20, and the comparison of this value and the simulated value is shown in Table 8 . It can conclude that the instantaneous power readings produced were not well 


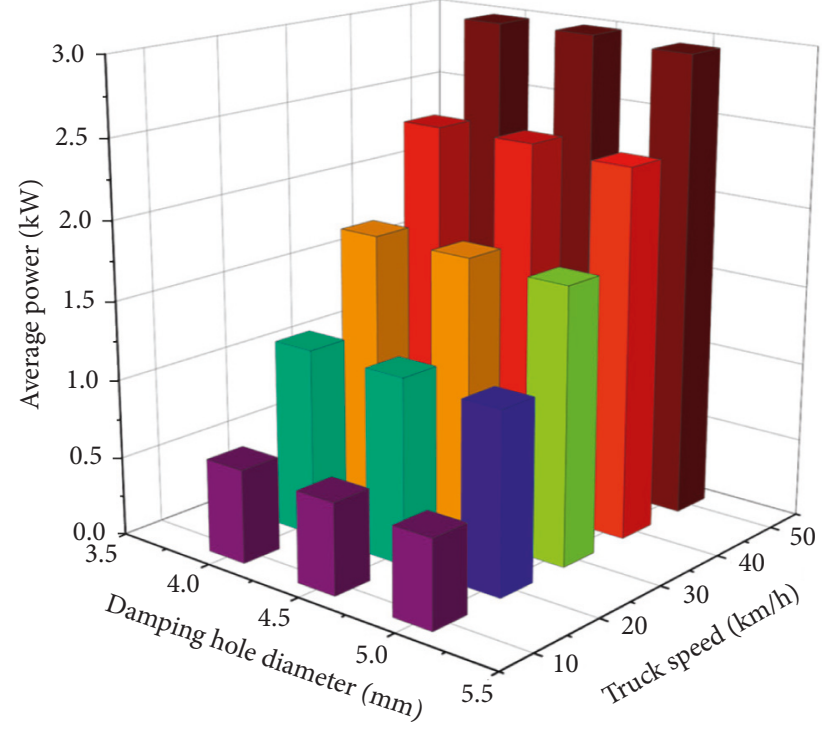

(a)

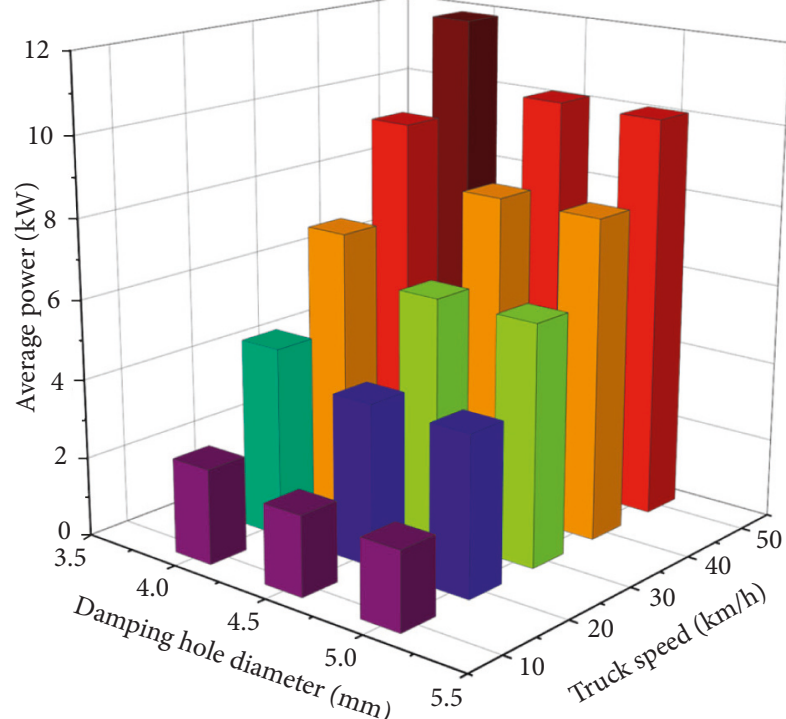

(b)

Figure 14: Average power comparison with different damping holes. (a) D-class road. (b) E-class road.

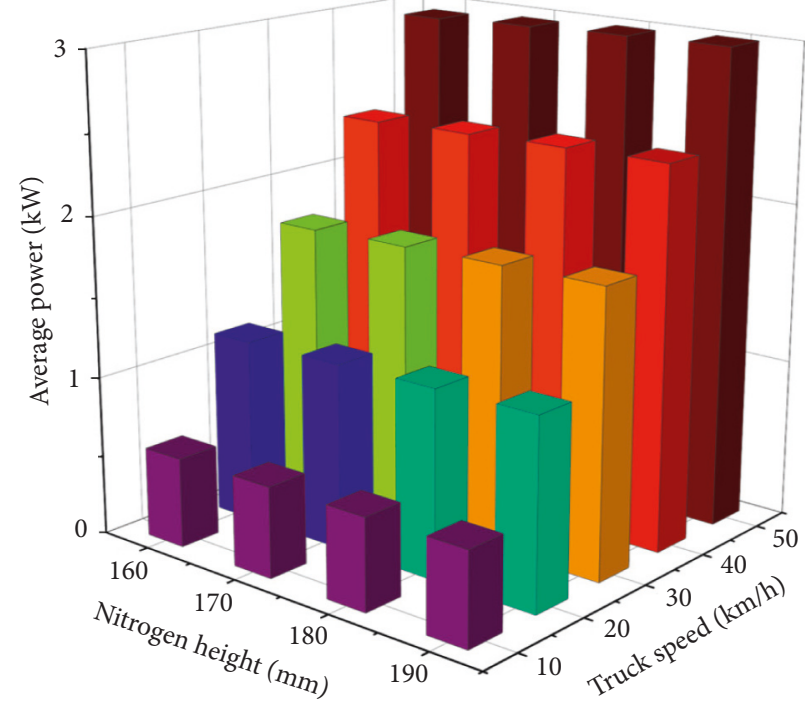

(a)

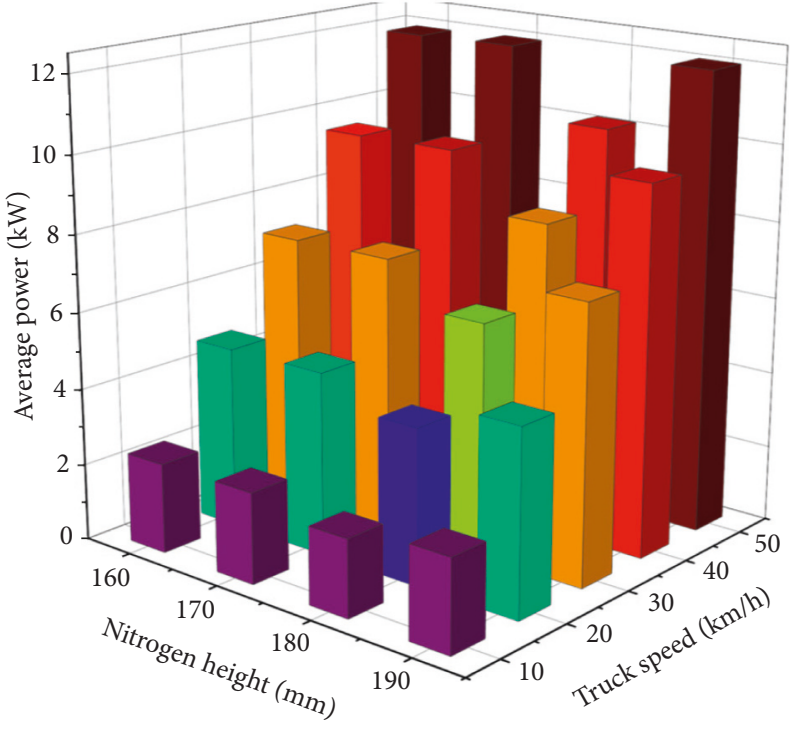

(b)

FIGURE 15: Average power comparison with different nitrogen heights. (a) D-class road. (b) E-class road.

matched, but that the average power readings matched very well. The average power produced at these speeds is about $35 \mathrm{~kW}$. The maximum power of the electrical system of the truck is about $120 \mathrm{~kW}$, and the average power is about $40 \mathrm{~kW}$; the harvested power can be provided to the electrical system and is the harvested power almost sufficient to run the electrical system.

Table 9 shows the instantaneous power of the truck in different speeds and the potential fuel saving in theory. The energy transform efficiency is not considered, and it can be concluded from the table as follows:

(1) The fuel saving is increased as the truck speed increases from 10 to $30 \mathrm{~km} / \mathrm{h}$. But, as the truck speed increases continually, the fuel saving percentage stays constant.

(2) The results of simulation and the experiment matched well. The proposed quarter-truck model is suitable for these research studies. 
TABLe 4: Average power and RMS on different damping hole (E-class road).

\begin{tabular}{|c|c|c|c|c|c|}
\hline \multicolumn{6}{|l|}{$h_{0}=180 \mathrm{~mm}, d=4 \mathrm{~mm}$} \\
\hline Speed $(\mathrm{km} / \mathrm{h})$ & 10 & 20 & 30 & 40 & 50 \\
\hline Power $(\mathrm{kW})$ & 11.869 & 9.5322 & 7.1654 & 4.7826 & 2.3913 \\
\hline $\operatorname{RMS}\left(\mathrm{m} / \mathrm{s}^{2}\right)$ & 2.0873 & 1.9005 & 1.6843 & 1.4207 & 1.0675 \\
\hline Pearson correlation coefficient & 0.992212 & & & & \\
\hline$P$ value & $8.24 E-04$ & & & & \\
\hline \multicolumn{6}{|l|}{$h_{0}=180 \mathrm{~mm}, d=4.5 \mathrm{~mm}$} \\
\hline Power $(\mathrm{kW})$ & 10.128 & 8.1088 & 6.0858 & 4.059 & 2.017 \\
\hline $\operatorname{RMS}\left(\mathrm{m} / \mathrm{s}^{2}\right)$ & 2.0671 & 1.896 & 1.6982 & 1.4578 & 1.1282 \\
\hline Pearson correlation coefficient & 0.991414 & & & & \\
\hline$P$ value & $9.54 E-04$ & & & & \\
\hline \multicolumn{6}{|l|}{$h_{0}=180 \mathrm{~mm}, d=5 \mathrm{~mm}$} \\
\hline Power $(\mathrm{kW})$ & 10.09 & 8.0828 & 6.0613 & 4.0236 & 1.9812 \\
\hline $\operatorname{RMS}\left(\mathrm{m} / \mathrm{s}^{2}\right)$ & 2.1109 & 1.9569 & 1.776 & 1.5495 & 1.2269 \\
\hline Pearson correlation coefficient & 0.989125 & & & & \\
\hline$P$ value & 0.00136 & & & & \\
\hline
\end{tabular}

TABLE 5: Average power and RMS on different nitrogen heights (E-class road).

\begin{tabular}{|c|c|c|c|c|c|}
\hline \multicolumn{6}{|l|}{$d=4.5 \mathrm{~mm}, h_{0}=160 \mathrm{~mm}$} \\
\hline Speed $(\mathrm{km} / \mathrm{h})$ & 10 & 20 & 30 & 40 & 50 \\
\hline Power $(\mathrm{kW})$ & 11.883 & 9.5056 & 7.1265 & 4.7444 & 2.3475 \\
\hline RMS $\left(\mathrm{m} / \mathrm{s}^{2}\right)$ & 2.164 & 1.9931 & 1.7954 & 1.5519 & 1.2116 \\
\hline Pearson correlation coefficient & 0.990312395 & & & & \\
\hline$P$ value & 0.00114 & & & & \\
\hline \multicolumn{6}{|l|}{$d=4.5 \mathrm{~mm}, h_{0}=170 \mathrm{~mm}$} \\
\hline Power $(\mathrm{kW})$ & 11.935 & 9.5522 & 7.1638 & 4.7753 & 2.3706 \\
\hline $\mathrm{RMS}\left(\mathrm{m} / \mathrm{s}^{2}\right)$ & 2.1135 & 1.9424 & 1.7447 & 1.5028 & 1.1676 \\
\hline Pearson correlation coefficient & 0.990820145 & & & & \\
\hline$P$ value & 0.00105 & & & & \\
\hline \multicolumn{6}{|l|}{$d=4.5 \mathrm{~mm}, h_{0}=180 \mathrm{~mm}$} \\
\hline Power $(\mathrm{kW})$ & 10.128 & 8.1088 & 6.0858 & 4.059 & 2.017 \\
\hline $\operatorname{RMS}\left(\mathrm{m} / \mathrm{s}^{2}\right)$ & 2.0671 & 1.896 & 1.6982 & 1.4578 & 1.1282 \\
\hline Pearson correlation coefficient & 0.991414338 & & & & \\
\hline$P$ value & $9.54 E-04$ & & & & \\
\hline \multicolumn{6}{|l|}{$d=4.5 \mathrm{~mm}, h_{0}=190 \mathrm{~mm}$} \\
\hline Power $(\mathrm{kW})$ & 12.011 & 9.6201 & 7.2169 & 4.8148 & 2.4034 \\
\hline $\operatorname{RMS}\left(\mathrm{m} / \mathrm{s}^{2}\right)$ & 2.0243 & 1.8531 & 1.6555 & 1.4165 & 1.0921 \\
\hline Pearson correlation coefficient & 0.991782568 & & & & \\
\hline$P$ value & $8.93 E-04$ & & & & \\
\hline
\end{tabular}

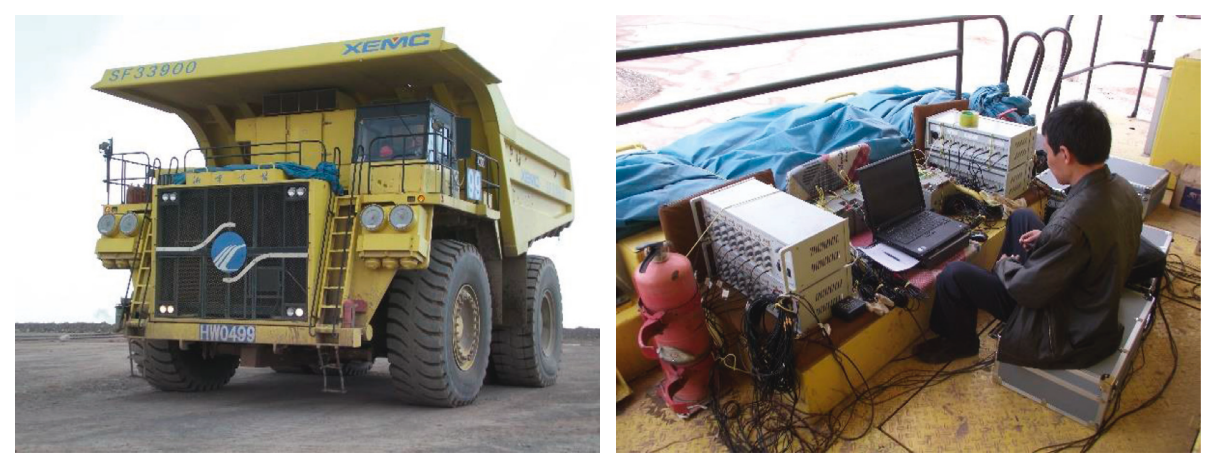

Figure 16: Mining dump truck and measurement instrumentations. 
TABLe 6: Experiment devices.

\begin{tabular}{lc}
\hline Experiment devices & Assignment \\
\hline Battery and invertor & Supplying energy for the device \\
Accelerometer, $400 \mathrm{pC} / \mathrm{g}, 0.05-500 \mathrm{~Hz}$ & Measuring the acceleration \\
Amplifier & Amplifying the measured signal \\
Recorder, MR30 C & Recording the signal \\
Data analysis device and software, SD380 & Analyzing the signal \\
\hline
\end{tabular}

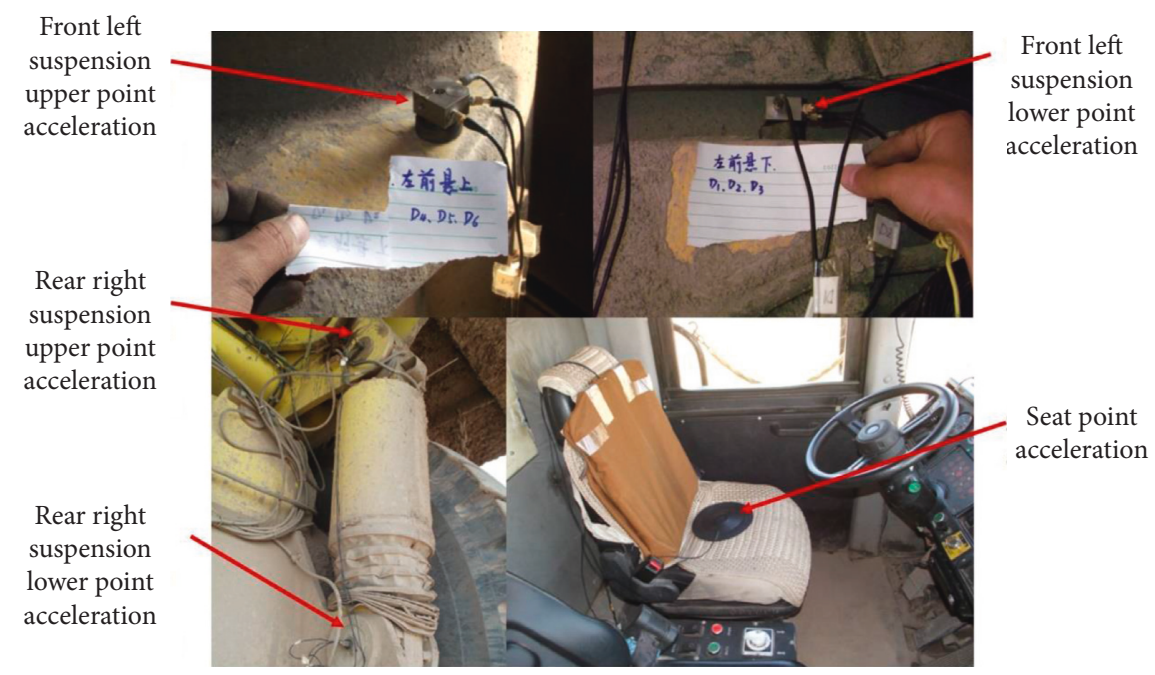

FIGURE 17: Schematic diagram of the measurement point.

TABLE 7: Location of the acceleration sensors.

Group 1 (10 measuring points)

Back of the seat

Floor of the driver's feet

Lower front suspension mounting point (left and right)

Front wheel's center (left and right)

Cushion of the seat

The deck center

Upper front suspension mounting point (left and right)

Group 2 (8 measuring points)

Front upper mounting point of powertrain (left and right)

Front lower mounting point of powertrain (left and right)

Rear upper mounting point of powertrain (left and right)

Rear lower mounting point of powertrain (left and right)

Group 3 (8 measuring points)

Lower rear suspension mounting point (left and right)

Left face of main frame

Left face of horizontal frame

Upper rear suspension mounting point (left and right)

Right face of main frame

Right face of horizontal frame

Group 4 (8 measuring points)

The front of the cab (left and right)

The middle of the (left and right)

The rear of the (left and right)

The deck (front and rear)

\section{Conclusion}

A mathematical model of a mining truck with nonlinear HPS was formulated to research the discipline of HPS of a mining dump truck. For a random road, the value of the harvested energy was calculated for the driving speeds between 10 and $50 \mathrm{~km} / \mathrm{h}$ for two roads during the simulations. However, a speed range of $10-30 \mathrm{~km} / \mathrm{h}$ was proposed during the real-drive field test, and the acceleration of some key locations such as suspension installation points were measured. The value of dissipated energy of the two research works is calculated; it is matching well. From this work, the following conclusions can be drawn.

The more irregular the road surface, the more the vibrational energy can be harvested from the suspension. The suspension will dissipate 4 times of energy when running on the E-class road than on the D-class road.

The instantaneous power (The peak value is $180 \mathrm{~kW}$.) is 15 times as the average power $(12 \mathrm{~kW})$ when running on the same road. It may conclude that the thermoelectric energy harvesting system is more suitable for the mining dump truck than other energy harvesting systems for the energy storing ability.

As the truck speed increased from 10 to $50 \mathrm{~km} / \mathrm{h}$, the average power increases approximately linearly for both the simulation and the test results; this was also true for the 


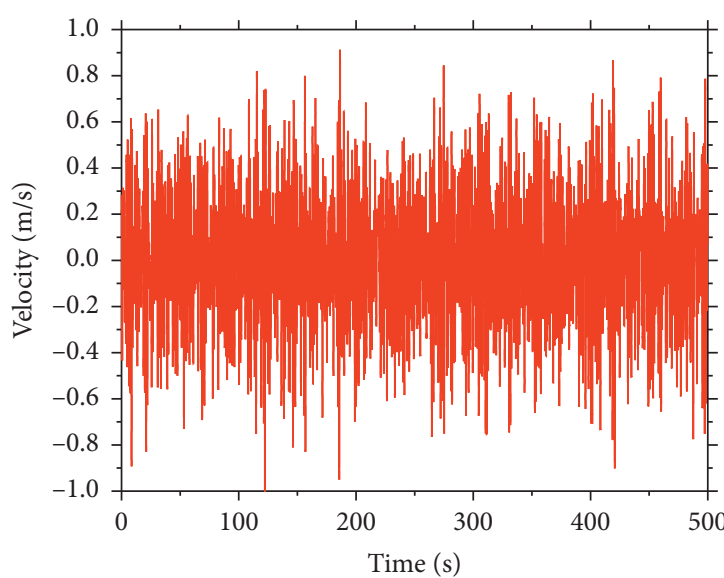

— Simulated velocity

(a)

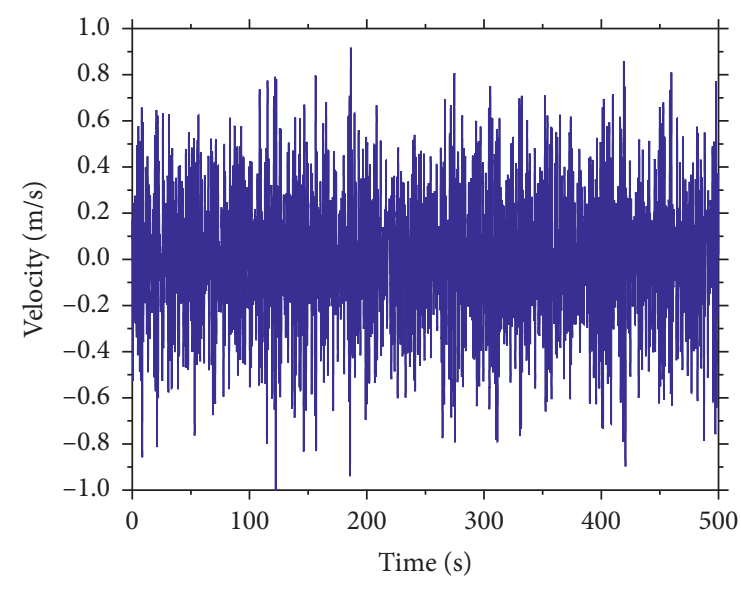

- Integrated velocity

(b)

FIgURE 18: Verification of the integration method. (a) Velocity by simulation. (b) Velocity by integration.
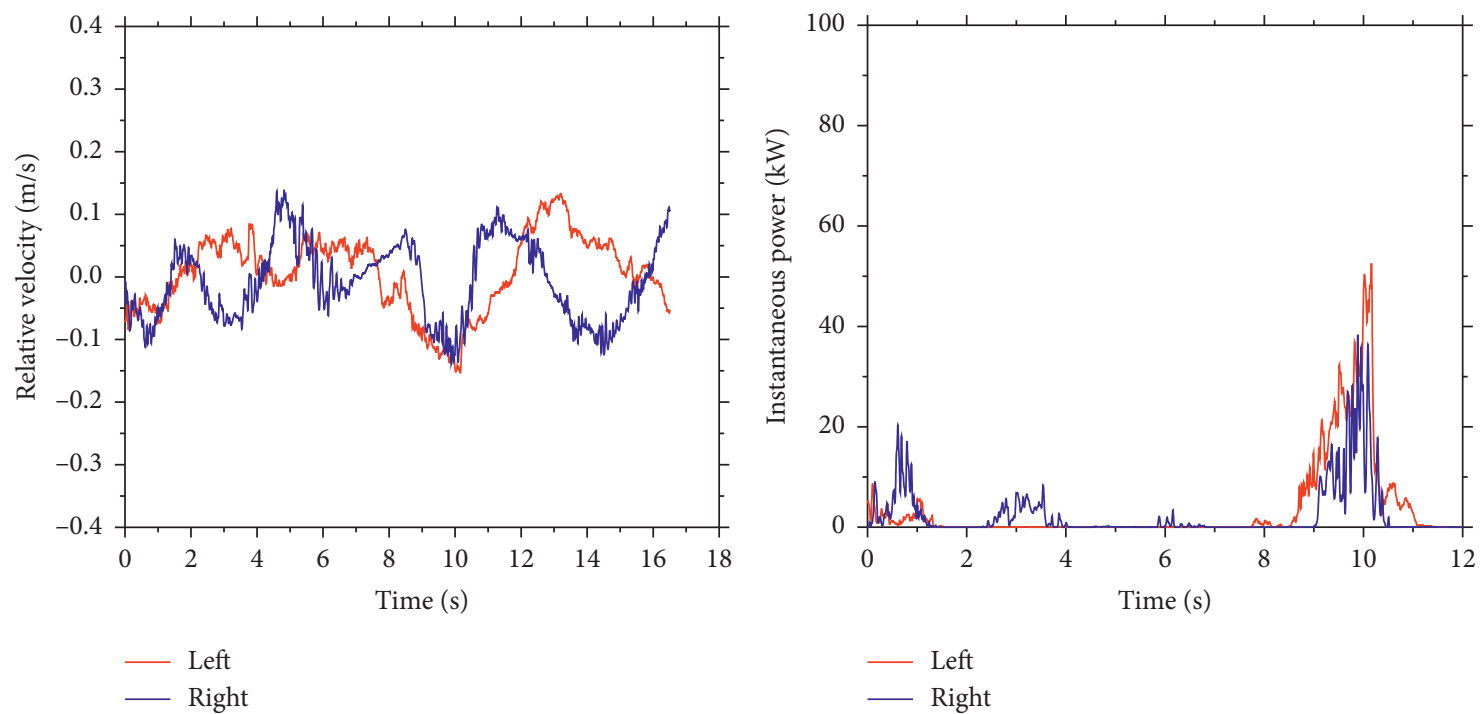

(a)
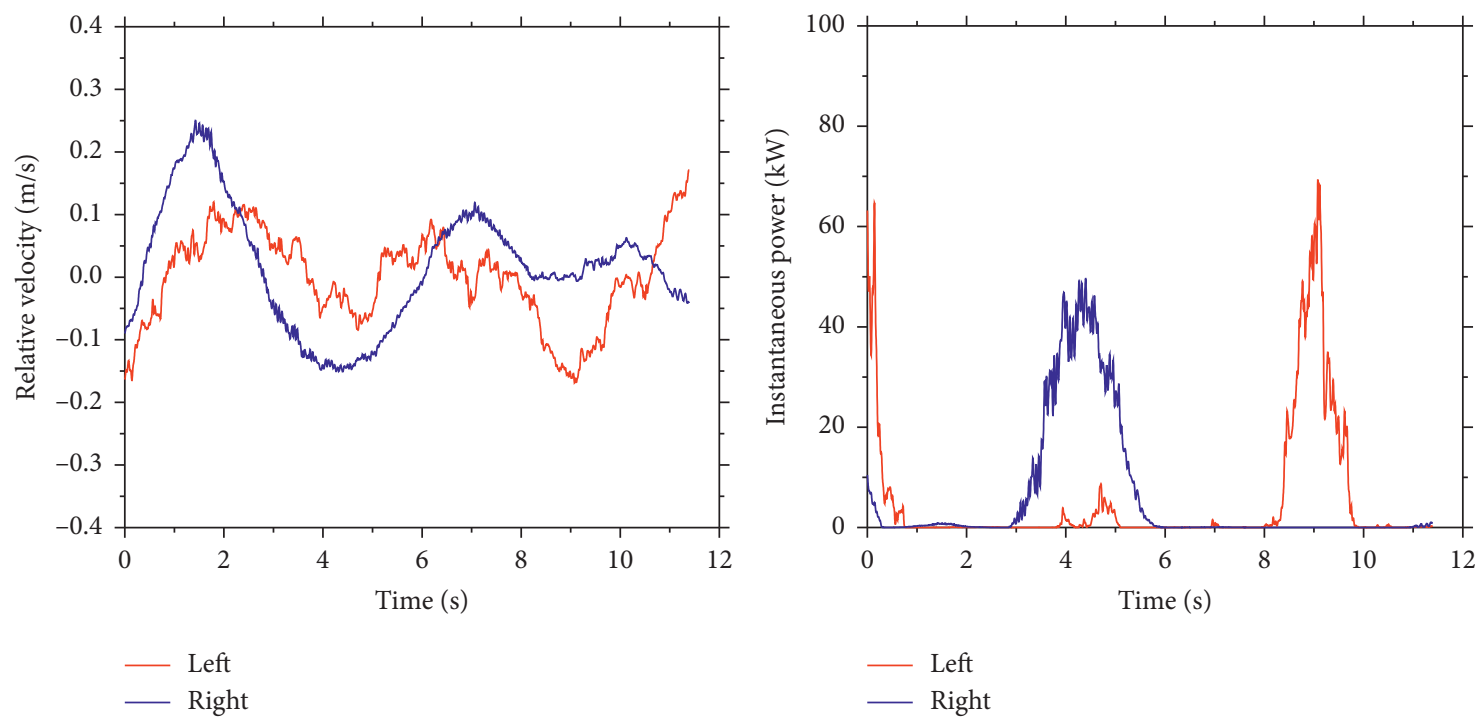

(b)

Figure 19: Continued. 

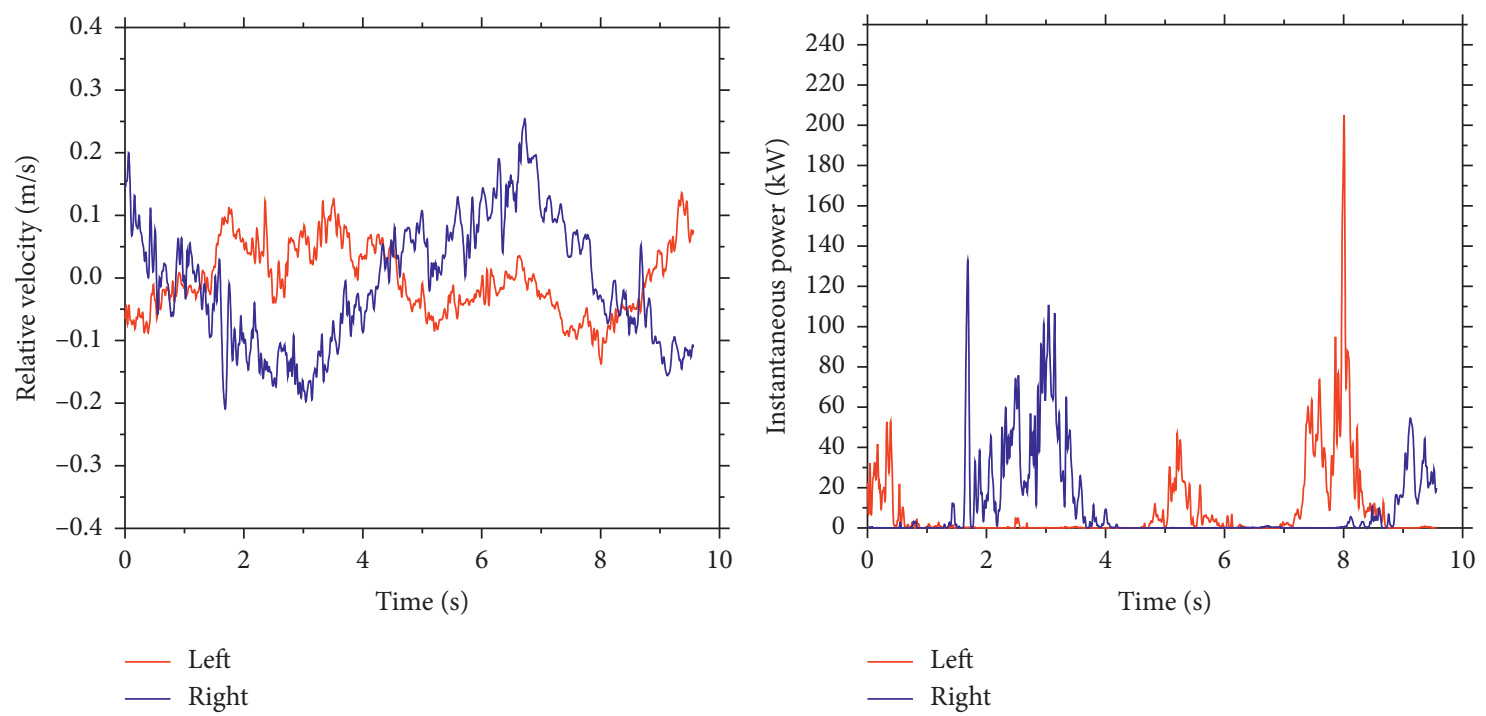

(c)

Figure 19: Relative velocity of front suspensions and instantaneous power dissipated by front suspensions. (a) $10 \mathrm{~km} / \mathrm{h}$. (b) $20 \mathrm{~km} / \mathrm{h}$. (c) $30 \mathrm{~km} / \mathrm{h}$.

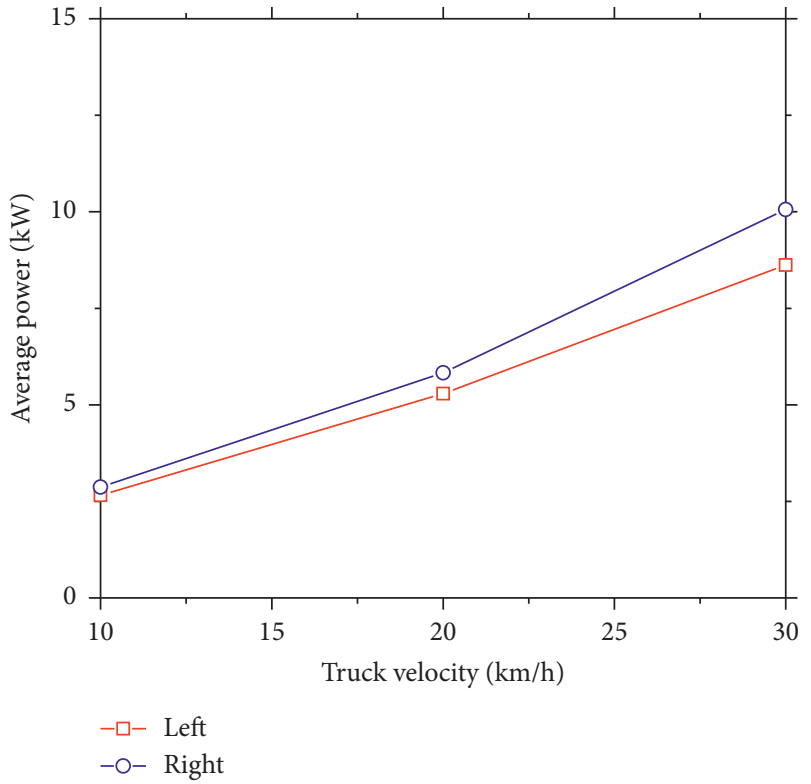

Figure 20: Average power dissipated by front suspensions.

TABLE 8: Peak power and average of the experiment.

\begin{tabular}{lcccc}
\hline $\begin{array}{l}\text { Truck } \\
\text { velocity }\end{array}$ & $\begin{array}{c}\text { Maximum } \\
\text { instantaneous } \\
\text { power }(\mathrm{kW})\end{array}$ & \multicolumn{2}{c}{$\begin{array}{c}\text { Average } \\
\text { power }(\mathrm{kW})\end{array}$} \\
\hline $10 \mathrm{~km} / \mathrm{h}$ & Simulation & Experiment & Simulation & Experiment \\
$20 \mathrm{~km} / \mathrm{h}$ & 98 & 55 & 9.6 & 10.6 \\
$30 \mathrm{~km} / \mathrm{h}$ & 127 & 207 & 19.6 & 21.2 \\
\hline
\end{tabular}

different road classes. The results show that harvested energy can reduce the total oil consumption of the truck by around $4 \%$. As the vehicle speed increases, the fuel saving proportion nearly stays constant.
TABLE 9: Fuel saving percentage in theory.

\begin{tabular}{lccccc}
\hline Truck velocity $(\mathrm{km} / \mathrm{h})$ & 10 & 20 & 30 & 40 & 50 \\
\hline Truck power $(\mathrm{kW})$ & 341 & 578 & 821 & 1074 & 1340 \\
Fuel saving by simulation (\%) & 2.8 & 3.4 & 3.5 & 3.5 & 3.5 \\
Fuel saving by test (\%) & 3.1 & 3.7 & 4.2 & - & - \\
\hline
\end{tabular}

However, the efficiency of the energy harvesting system was not considered in this article; in the future research work, the actual system efficiency and the harvested energy should be verified, and the energy harvesting efficiency of this method should be compared with others. Furthermore, the influence of energy harvesting system to the characteristic of the HPS would be considered.

\section{Data Availability}

All data included in this study are available upon request by contact with the corresponding author.

\section{Conflicts of Interest}

The authors declare that they have no conflicts of interest.

\section{Acknowledgments}

Special thanks are due to the National Natural Science Foundation of China (51705035), the Natural Science Foundation of Hunan Province (2017JJ3336), and the Science research foundation of the Education Department of Hunan Province (16C0062). The contribution was also supported by XEMC.

\section{References}

[1] IEA, 2018, https://www.iea.org/oilmarketreport/omrpublic/.

[2] X. D. Xie and Q. Wang, "Energy harvesting from a vehicle suspension system," Energy, vol. 86, pp. 385-392, 2015. 
[3] C. Wei and H. Taghavifar, "A novel approach to energy harvesting from vehicle suspension system: half-vehicle model," Energy, vol. 134, pp. 279-288, 2017.

[4] P. Múčka, "Energy-harvesting potential of automobile suspension," Vehicle System Dynamics, vol. 54, no. 12, pp. 1651-1670, 2016.

[5] X. Wang, Frequency Analysis of Vibration Energy Harvesting Systems, Elsevier, Amsterdam, Netherlands, 2016.

[6] M. Löhndorf, T. Kvisterøy, E. Westby, and E. Halvorsen, "Evaluation of energy harvesting concepts for tire pressure monitoring systems," in Proceedings of the Technical Digest PowerMEMS 2007, pp. 331-334, Freiburg, Germany, November 2007.

[7] F. Khameneifar and S. Arzanpour, "Energy harvesting from pneumatic tires using piezoelectric transducers," in Proceedings of the ASME 2008 Conference on Smart Materials, American Society of Mechanical Engineers (ASME), Adaptive Structures and Intelligent Systems, pp. 331-337, Ellicott City, MD, USA, January 2008.

[8] Q. Zheng, H. Tu, A. Agee, and Y. Xu, "Vibration energy harvesting device based on asymmetric air-spaced cantilevers for tire pressure monitoring system," in Proceedings of Power MEMS, pp. 403-406, Washington DC, USA, December 2009.

[9] L. Wu, Y. Wang, C. Jia, and C. Zhang, "Battery-less piezoceramics mode energy harvesting for automobile TPMS," in Proceedings of the 2009 IEEE 8th International Conference on ASIC ASICON'09, pp. 1205-1208, IEEE 8th International Conference, Changsha, China, December 2009.

[10] D. Younesian and M. R. Alam, "Multi-stable mechanisms for high-efficiency and broadband ocean wave energy harvesting," Applied Energy, vol. 197, pp. 292-302, 2017.

[11] R. Alamian, R. Shafaghat, S. J. Miri, N. Yazdanshenas, and M. Shakeri, "Evaluation of technologies for harvesting wave energy in Caspian Sea," Renewable and Sustainable Energy Reviews, vol. 32, pp. 468-476, 2014.

[12] X.-B. Shan, S.-W. Guan, Z.-S. Liu, Z.-1. Xu, and T. Xie, "A new energy harvester using a piezoelectric and suspension electromagnetic mechanism," Journal of Zhejiang University Science A, vol. 14, no. 12, pp. 890-897, 2013.

[13] L. E. Bell, "Cooling, heating, generating power, and recovering waste heat with thermoelectric systems," Science, vol. 321, no. 5895, pp. 1457-1461, 2008.

[14] E. F. Thacher, B. T. Helenbrook, M. A. Karri, and C. J. Richter, "Testing of an automobile exhaust thermoelectric generator in a light truck," in Proceedings of the Institution of Mechanical Engineers, Part D: Journal of Automobile Engineering, vol. 221, no. 1, pp. 95-107, 2007.

[15] Y. Wang, C. Dai, and S. Wang, "Theoretical analysis of a thermoelectric generator using exhaust gas of vehicles as heat source," Applied Energy, vol. 112, pp. 1171-1180, 2013.

[16] X. Liu, Y. D. Deng, Z. Li, and C. Q. Su, "Performance analysis of a waste heat recovery thermoelectric generation system for automotive application," Energy Conversion and Management, vol. 90, pp. 121-127, 2015.

[17] Y. Wang, Y. Tang, Y. Deng, and C. Su, "Numerical investigation on the performance of an automotive thermoelectric generator with exhaust-module-coolant direct contact," Journal of Electronic Materials, vol. 47, no. 6, pp. 3330-3337, 2018.

[18] M. A. A. Abdelkareem, L. Xu, M. K. A. Ali et al., "Vibration energy harvesting in automotive suspension system: a detailed review," Applied Energy, vol. 229, pp. 672-699, 2018.

[19] M. A. A. Abdelkareem, L. Xu, M. K. A. Ali et al., "Analysis of the prospective vibrational energy harvesting of heavy-duty truck suspensions: a simulation approach," Energy, vol. 173, pp. 332-351, 2019.

[20] N. V. Satpute, S. Singh, and S. M. Sawant, "Energy harvesting shock absorber with electromagnetic and fluid damping," Advances in Mechanical Engineering, vol. 6, Article ID 693592, 2015.

[21] Z. Li, L. Zuo, G. Luhrs, L. Lin, and Y.-X. Qin, "Electromagnetic energy-harvesting shock absorbers: design, modeling, and road tests," IEEE Transactions on Vehicular Technology, vol. 62, no. 3, pp. 1065-1074, 2013.

[22] B. Howard, Bose Sells Off Its Revolutionary Electromagnetic Suspension, 2017, https://www.extremetech.com/extreme/259042bose-sells-off-revolutionary-electromagnetic-suspension.

[23] Z. Zhang, X. Zhang, W. Chen et al., "A high-efficiency energy regenerative shock absorber using supercapacitors for renewable energy applications in range extended electric vehicle," Applied Energy, vol. 178, pp. 177-188, 2016.

[24] Y. Zhang, H. Chen, K. Guo, X. Zhang, and S. E. Li, "Electrohydraulic damper for energy harvesting suspension: modeling, prototyping and experimental validation," Applied Energy, vol. 199, pp. 1-12, 2017.

[25] Y. Zhang, X. Zhang, M. Zhan, K. Guo, F. Zhao, and Z. Liu, "Study on a novel hydraulic pumping regenerative suspension for vehicles," Journal of the Franklin Institute, vol. 352, no. 2, pp. 485-499, 2015.

[26] Y. Zhang, K. Guo, D. Wang, C. Chen, and X. Li, "Energy conversion mechanism and regenerative potential of vehicle suspensions," Energy, vol. 119, pp. 961-970, 2017.

[27] F. Khoshnoud, D. B. Sundar, M. N. M. Badi, Y. K. Chen, R. K. Calay, and C. W. De Silva, "Energy harvesting from suspension systems using regenerative force actuators," International Journal of Vehicle Noise and Vibration, vol. 9, no. 3-4, pp. 294-311, 2013.

[28] M. A. Abdelkareem, L. Xu, M. K. A. Ali, M. A. Hassan, A. Elagouz, and J. Zou, "On-field measurements of the dissipated vibrational power of an SUV car traditional viscous shock absorber," in Proceedings of the ASME 2018 International Design Engineering Technical Conferences and Computers and Information in Engineering Conference, American Society of Mechanical Engineers (ASME), Quebec City, Quebec, Canada, August 2018.

[29] P. Múčka, "Current approaches to quantify the longitudinal road roughness," International Journal of Pavement Engineering, vol. 17, no. 8, pp. 659-679, 2016.

[30] P. Múčka, "Simulated road profiles according to ISO 8608 in vibration analysis," Journal of Testing and Evaluation, vol. 46, no. 1, pp. 405-418, 2017.

[31] D. S. Paraforos, H. W. Griepentrog, and S. G. Vougioukas, "Country road and field surface profiles acquisition, modelling and synthetic realisation for evaluating fatigue life of agricultural machinery," Journal of Terramechanics, vol. 63, pp. 1-12, 2016.

[32] M. Peter, "Influence of profile specification on international roughness index," Journal of Infrastructure Systems, vol. 25, no. 2, Article ID 04019005, 2019. 


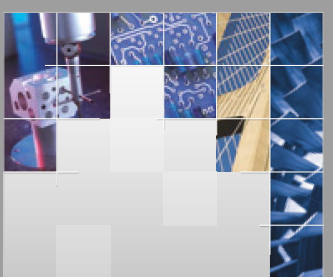

\section{Enfincering}
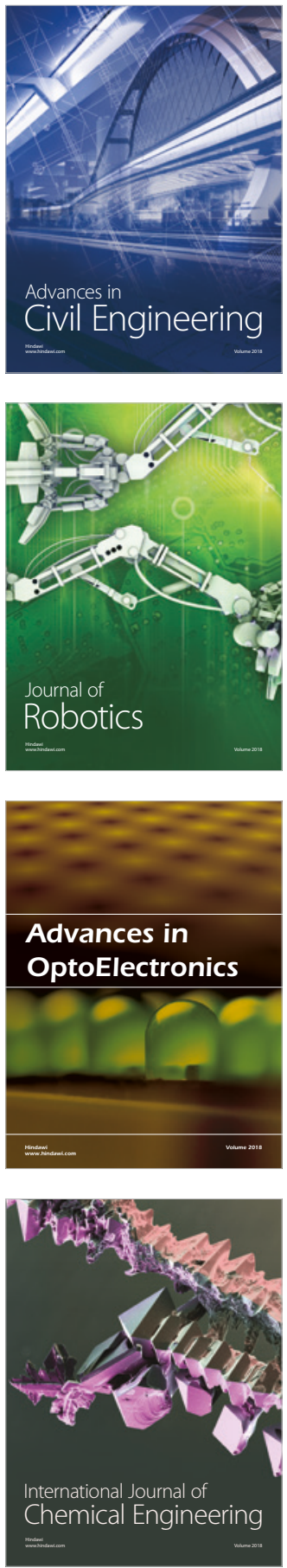

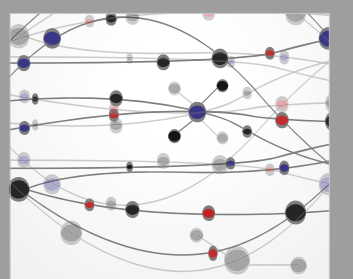

\section{Rotating \\ Machinery}

The Scientific World Journal

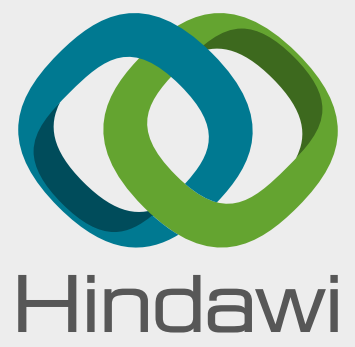

Submit your manuscripts at

www.hindawi.com
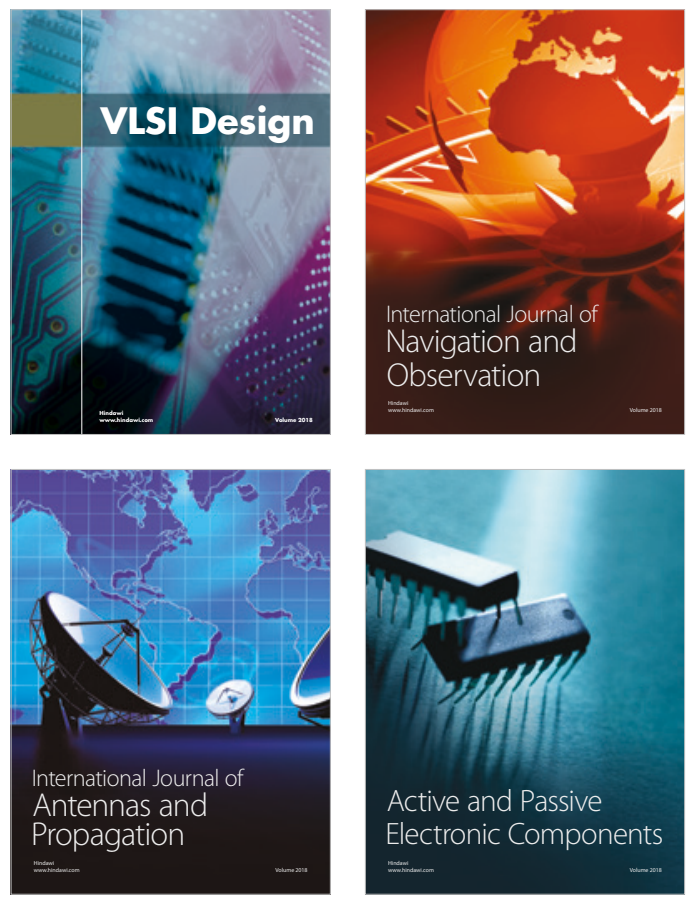
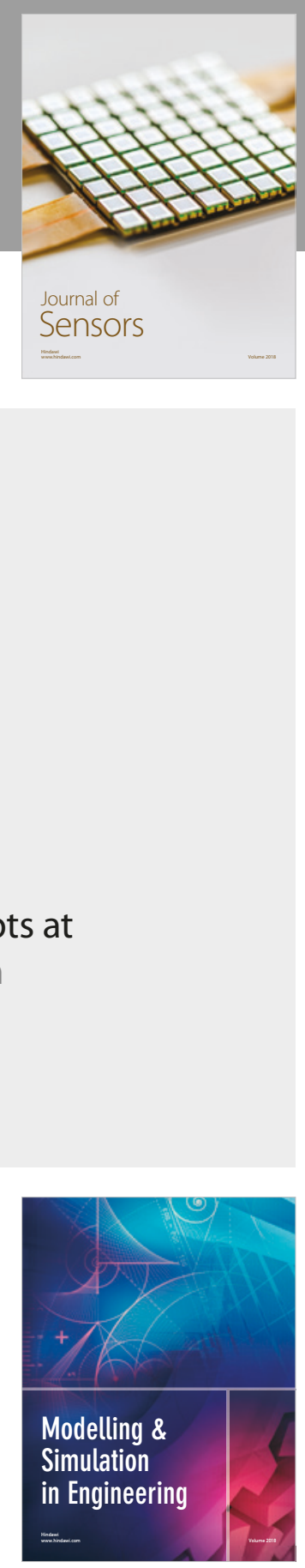

\section{Advances \\ Multimedia}
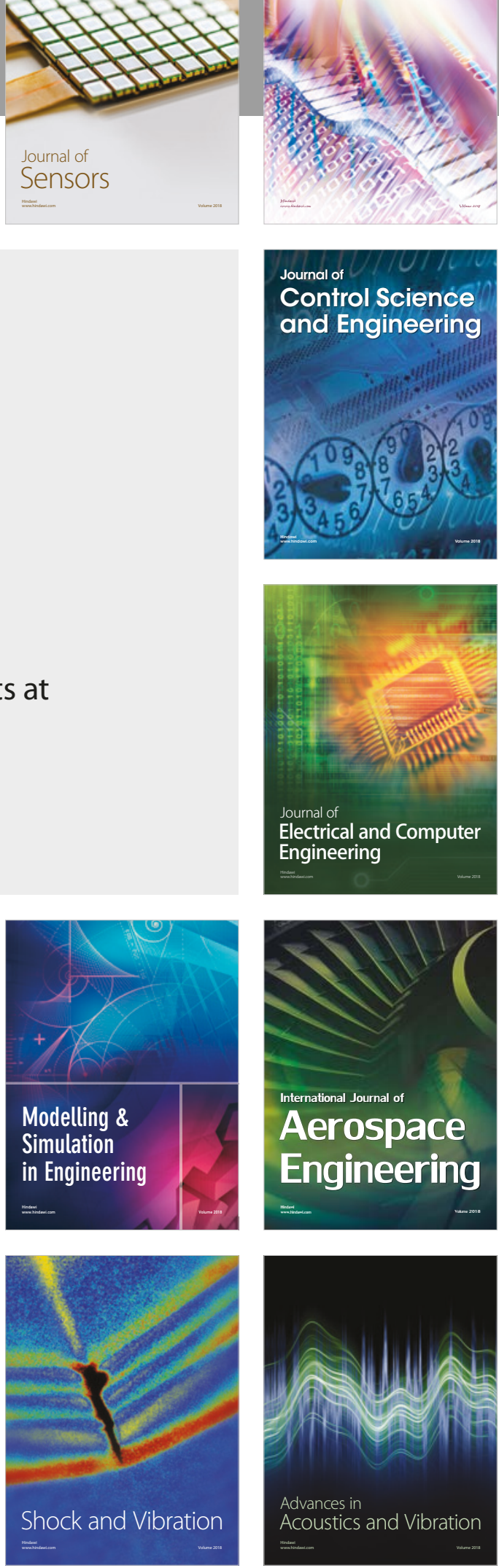